\title{
Tomographic Image of the Southern California Mantle
}

\author{
EUGENE D. HUMPHREYS \\ Department of Geological Sciences, University of Oregon, Eugene \\ ROBERT W. Clayton \\ Seismological Laboratory, California Institute of Technology, Pasadena
}

\begin{abstract}
$P$ wave teleseismic travel time delays recorded by the Southem Califomia Array are inverted by the method of backprojection tomography to obtain images of variations in the $P$ wave velocity structure to a depth of $750 \mathrm{~km}$. Two major upper mantle features are resolved: one beneath the Transverse Ranges region and another beneath the Salton Trough region. The Transverse Ranges feature ppears as a curtainlike, east trending, high-velocity anomaly. This feature is $-60 \mathrm{~km}$ thick, extends most deeply on its eastem end (to $-250 \mathrm{~km}$ ), and attains a maximum velocity $-3 \%$ greater than average southem Califomia mantle of the same depth. The Salton Trough feature, which is not as well resolved as the Transverse Ranges feature, is composed of low velocities in the upper $70-100 \mathrm{~km}$. These $P$ wave velocities are depressed $3-4 \%$ compared to average southem Califomia mantle. Tests of the inversion indicate the major aspects of the imaged structure are authentic.
\end{abstract}

\section{INTRODUCTION}

The high-resolution seismic imaging of western United States upper mantle structure is unsurpassed. This has been made possible through the tomographic inversion of teleseismic $\boldsymbol{P}$ delays recorded by the many regional arrays operated within the western United States. Because $P$ wave arrivals are easy to pick accurately and because teleseismic sources are abundant, data quality is typically very good. Hence most aspects of these inversions are well resolved. A major result of western United States studies is that the upper mantle structure is highly heterogeneous, exhibiting a strong correlation with both active surface tectonism near the plate margin [Humphreys et al., 1984; Ramussen and Humphreys, 1988] and volcanism within the continental interior [Evans, 1982; Lyer, 1984; Parker et al., 1984; Dueker and Humphreys, 1990)].

In this paper we reexamine teleseismic $\boldsymbol{P}$ delays derived from the Southern California Seismic Array. Of the western United States arrays, the data provided by this array is the most extensive (in the number and distribution of both stations and sources), and hence the structure there can be resolved best. The first study of southern Califomia upper mantle structure based on teleseismic $P$ delays was that of Hadley and Kanamori [1977], who discussed the $P$ delay map resulting from $P K I K P$ arrivals originating from an earthquake in Sumatra $\left(\Delta=120^{\circ}\right)$. Rays associated with these arrivals are nearly vertical, and thus indicate the $P$ wave velocity variations roughly beneath the stations. The most prominent feature observed by Hadley and Kanamori [1977] is an area coinciding approximately with the Transverse Ranges that has arrivals $0.5-1.0 \mathrm{~s}$ early relative to other southem Califomia stations. They deduced that relative delays arise from anomalous structure located beneath the crust

Copyright 1990 by American Geophysical Union.

Peper number 90JB01385.

$0148-0227 / 90 / 90 \mathrm{JB}-01385 \$ 05.00$ because the observed delay pattern extends across the surface trace of the San Andreas fault. (see Figure 1 for locations of major geographic and tectonic regions of southern California.)

In a later study, Raikes [1980] examined teleseismic $P$ arrivals from a variety of back azimuths. She used the least squares block model of Aki et al. [1977] to invert for strucrure above a depth of $150 \mathrm{~km}$. Her results indicate that the anomalous high-velocity mantle beneath the Transverse Ranges extends to a depth of at least $150 \mathrm{~km}$. She also found the uppermost mantle beneath the Salton Trough anomalously low in $P$ wave velocity. Walck and Minster [1982] reanalyzed Raikes' data using a method in which wave front distortion is estimated and ascribed to a thin lens of arbitrary depth. They concluded that if all wavefront refraction is atributed to ray bending at a single depth, this depth must be greater than 100 km, possibly much greater. Humphreys et al. [1984] augmented Raikes' data with additional sources and inverted these data with the method of backprojection tomography. They found anomalously high velocities extending to $-250 \mathrm{~km}$ depth beneath the Transverse Ranges and anomalously low velocities extending to $-100 \mathrm{~km}$ beneath the Salton Trough region.

The spatial association of mantle features with major surface provinces is impressive. To date, the Transverse Ranges anomaly has received the most attention. Bird and Rosenstock [1984] proposed a kinematic model in which the lithosphere there is converging, with the subcrustal portion descending beneath the ranges. They attribute the high seismic velocity of the anomaly to low temperature. Others have proposed models in which the entire lithosphere, including the crush, is descending beneath the Transverse Ranges [Sheffels and McNutt, 1986; Namson and Davis, 1988]. A more detailed image of the upper mantle can provide a basis for further considerations, including differentiating between these models as well as addressing processes active beneath the Salton Trough and elsewhere. In this paper we present images of the upper mantle with relatively high levels of resolution. This is achieved by incorporating core phases to Raikes' data set, so that it includes rays more nearly vertical in orientation than direct $P$ arrivals, and by dividing the subsurface into a greater number of smaller blocks than used by 


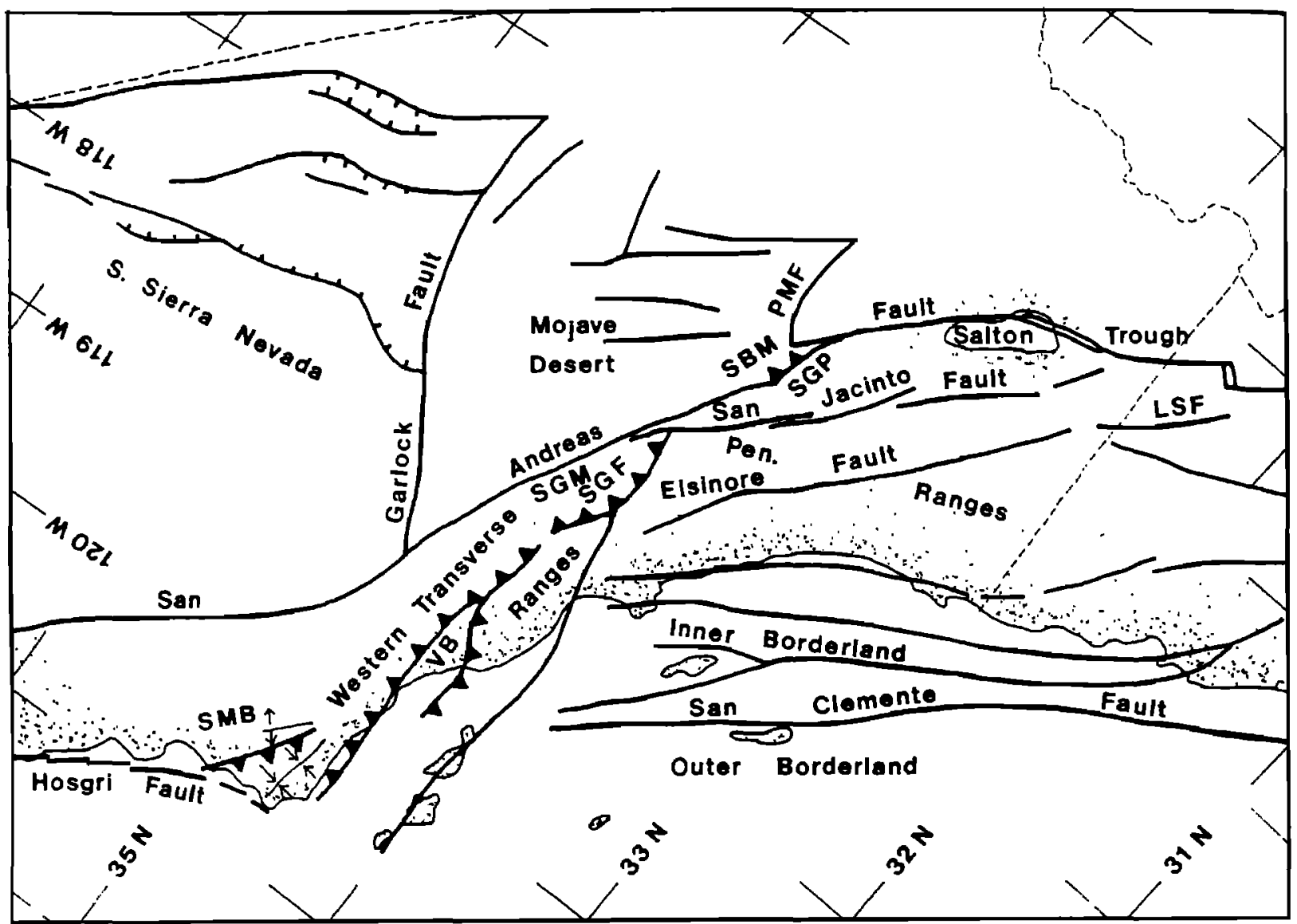

Fig. 1. Map showing geographic and tectonic features discussed in the text. The map is a Mercator projection about the NUVEL-1 [DeMets et al., 1987] Pacific-North America pole. Symbols are LSF, Laguna Salada fault; PMF, Pinto Mountain fault; SBC, Santa Barbara Channel; SBM, San Bemardino Mountains SGF, San Gabriel-Sierra Madre-Cucamonga fault system; SGM, San Gabriel Mountains SGP, San Gorgonio Pass; SMB, Santa Maria Basin VB, Ventura Basin. The San Gabriel and San Bemardino Mountains comprise the central Transverse Ranges.

Humphreys et al. [1984]. That study included 2717 blocks 30 $\mathrm{km}$ on a side and $50 \mathrm{~km}$ deep, extending down to $525 \mathrm{~km}$. We here divide the same general region into 47,175 blocks $15 \mathrm{~km}$ on a side and $30 \mathrm{~km}$ deep, extending down $750 \mathrm{~km}$. Throughout much of our inversion domain we do not have sufficient data quality to resolve structure as small as the dimensions of the blocks chosen, and hence the results need to be sta bilized; however, resolution tests indicate that this small block size is meaningful within the central part of the inversion.

In the following sections we discuss the travel time data, its reduction and inversion, and resolution of the inversion.

\section{Data ReDuction}

The raw data consist of $P, P K P$, and $P K I K P$ arrival times. Figure $2 a$ shows the source distribution with an event map, and Figure $2 b$ presents the same information in back azimuth-ray parameter space. Back azimuth and ray parameter information are determined using the National Earthquake Information Service locations and the Herrin tables [Herrin, 1968]. Events of distance greater than $100^{\circ}$ (slowness less than $4 \mathrm{~s} / \mathrm{deg}$ ) provide the core phases. The data cover all quadrants and range in ray parameter from 0 to $10 \mathrm{~s} / \mathrm{deg}$. However, the south and NE directions are poorly represented relative to the NW and SE directions.
In all, we use about 160 events recorded by the Southem Califomia Array. Figure 3 shows a station location map for the year 1979. Station distribution has changed through time, but the coverage shown is typical for the period during which the data were recorded. Data from a total of 158 stations are included in this study. The number of stations providing usable records for any particular event varies, and the resulting data set consists of nearly 10,000 rays. Each station recorded an average of 63 events, while each event was recorded by an average of 61 stations.

To reduce the data to a set of travel time delays, we apply several standard corrections. These include elevation and sediment corrections (applied in the same manner as Raikes). Most of the stations to which sediment corrections have been assigned are in the Imperial Valley, and these corrections are consistent with the results of Fuis et al. [1983]. After applying these corrections, residuals are calculated by subtracting the Herrin travel times. Next, the average delay for each event is subtracted to reduce the effect of source parameter errors. An effect of this procedure is to remove the average seismic velocity from the inversion. The average arrival is about $2 \mathrm{~s}$ later than predicted by Herrin, and the generally late arrivals indicate a low average velocity for southern California upper mantle. Romanowicz [1979] and Dziewonski and Anderson [1983] have identified the mantle beneath the western United States as slow. 

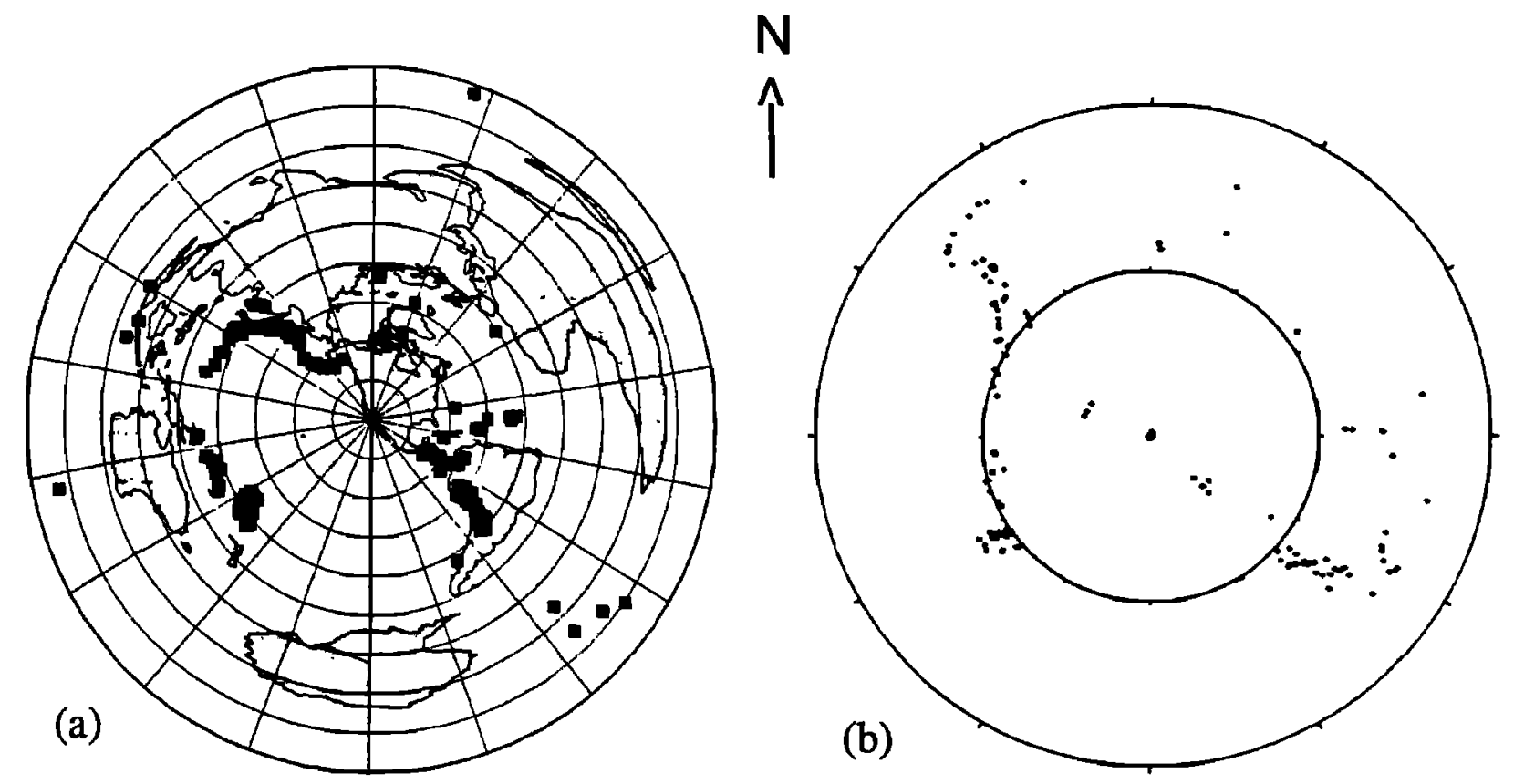

Fig. 2. Locations of the 163 events used in this study. (a) Map of the back aximuth- $\Delta$ location of the events. (b) Display of these events in ray parameter-azimuth space. In Figure $2 b$ the inner circle is 5 s/deg and the outer circle is $10 \mathrm{~s} / \mathrm{deg}$.

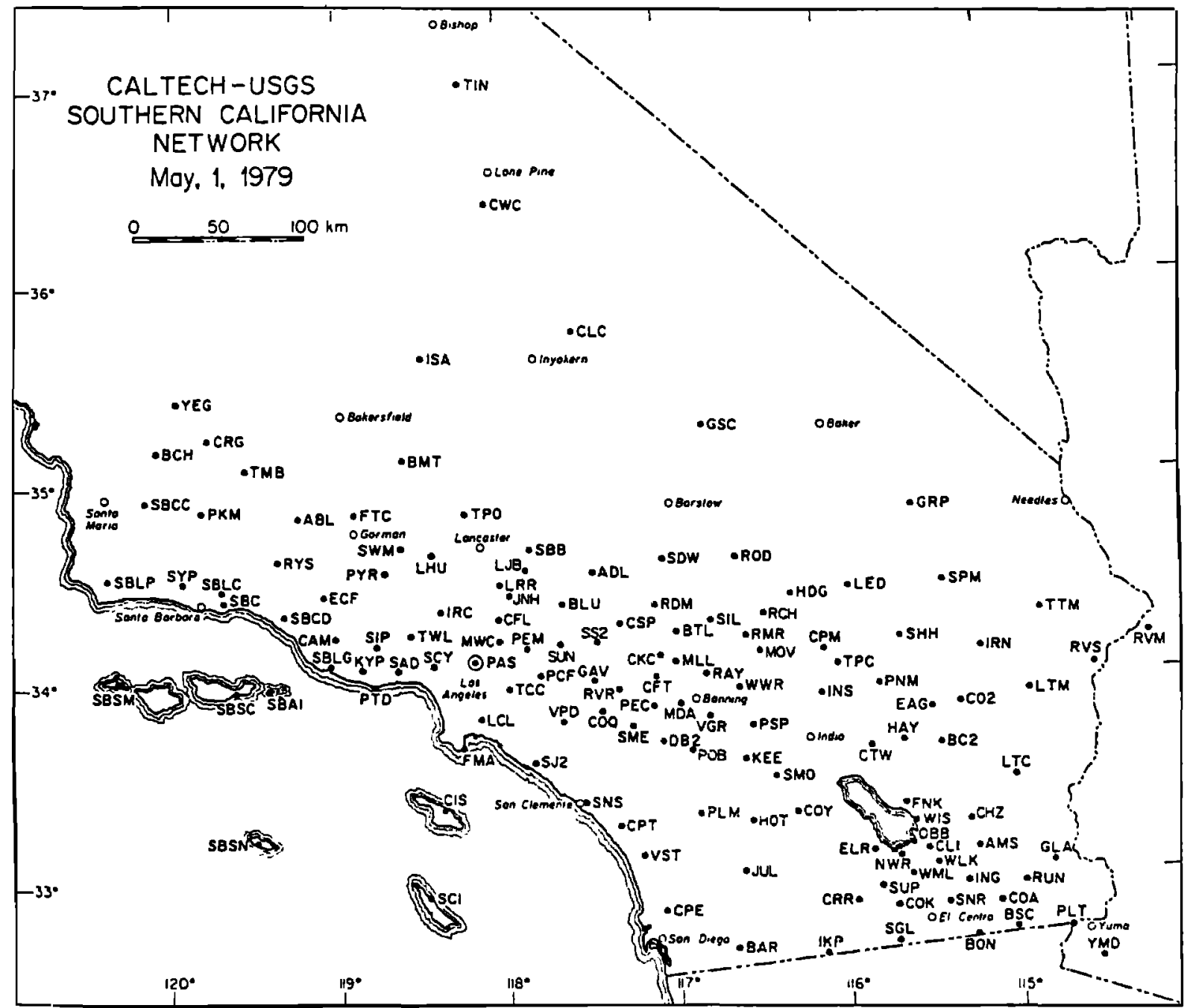

Fig. 3. Map of the Southem Califomia Seismic Array station location on May 1, 1979, which is representative of the station distribution during the period in which the dau used in this study were recorded. 
and the mantle beneath the southern California region as especially slow, compared to average global and cratonic United States velocities.

We reduce the core phases ( $P K P$ and $P K I K P$ ) differently than the direct- $P$ arrivals because Herrin reductions consistently underestimate $d T / d \Delta$ for these phases recorded at southem Califomia. We correct with the Herrin tables the arrival times for a large event $\left(m_{b}=6.1\right)$ that occurred very near the southem Califomia antipode $\left(\Delta \approx 175^{\circ}\right)$, and we use the resulting delay map as a reference. Herrin corrections cannot introduce large error in this case because $d T / d \Delta$ is known to be zero at the antipode. We then adjust the reduction value of $d T / d \Delta$ for each of the other core-penetrating events to best match the reference $P$ delay map in a least squares sense.

We also apply a correction for variable crustal thickness. To do this, we calculate a correction for teleseismic arrivals by assuming (1) the Moho is located at the depth implied by the station $\boldsymbol{P}_{n}$ time terms of Hearn [1984] and Hearn and Clayton [1986b], and (2) the velocity contrast across the Moho is 1.2 $\mathrm{km} / \mathrm{s}$. We then remove the mean from this set of values so that they represent only variations in crustal thickness and not the delay associated with the entire crust. The average absolute value of these corrections is $0.06 \mathrm{~s}$.

Actual $P_{n}$ station time terms arise from variations both in crustal velocity and in crustal thickness, but time terms are much more sensitive to changes in crustal thickness (because of its direct effect on ray length) than to reasonable variations in crustal velocities. In contrast, differences in teleseismic travel time delay are not as sensitive to total crustal thickness because Moho position simply determines where the ray passes from the upper mantle into the crust and thus detemines only the relative fraction of ray path in each material. On the other hand, both $P_{n}$ and teleseismic arrivals are equally sensitive to crustal velocity structure. Therefore, assuming that $P_{n}$ station time terms arise solely from Moho structure will underestimate the value of correction if delay actually arises from crustal structure. Therefore, if crustal structure is the cause of a delay, our crustal correction will be of the right sign but will be too small in absolute value. Applying a crustal correction in this way, then, should not contribute erroneous signal but only possibly underestimate the value of the crustal correction. If crustal corrections are misapplied, or they are not applied at all, the resulting erroneous delay values should produce erroneous model structure that is concentrated near the Moho, i.e., principally in the crustal and uppermost mantle layers of blocks, and should have little effect on the estimate of deeper structure.

Because the antipodal travel time residuals indicate the delay accumulated directly beneath each observation site and also because this event was exceptionally well recorded, this $P$ delay map is shown as an example (Figure 4a). For comparison, Figure $4 b$ shows the $P$ delay map resulting from an event of similar magnitude $\left(m_{b}=5.9\right)$ beneath Korea $\left(\Delta=82^{\circ}\right)$. Arrivals from this event are from WNW, and the general pattern is seen to shift toward ESE compared to the antipodal event.

\section{METHOD OF INVERSTON}

We employ backprojection tomography to invert the data The method is presented in detail by Humphreys and Clayton [1988], and only a brief outline is given here. Model parameterization is identical to that commonly used with the least squares approach: the region modeled is divided into a number of discrete blocks, and the slowness perturbations of these
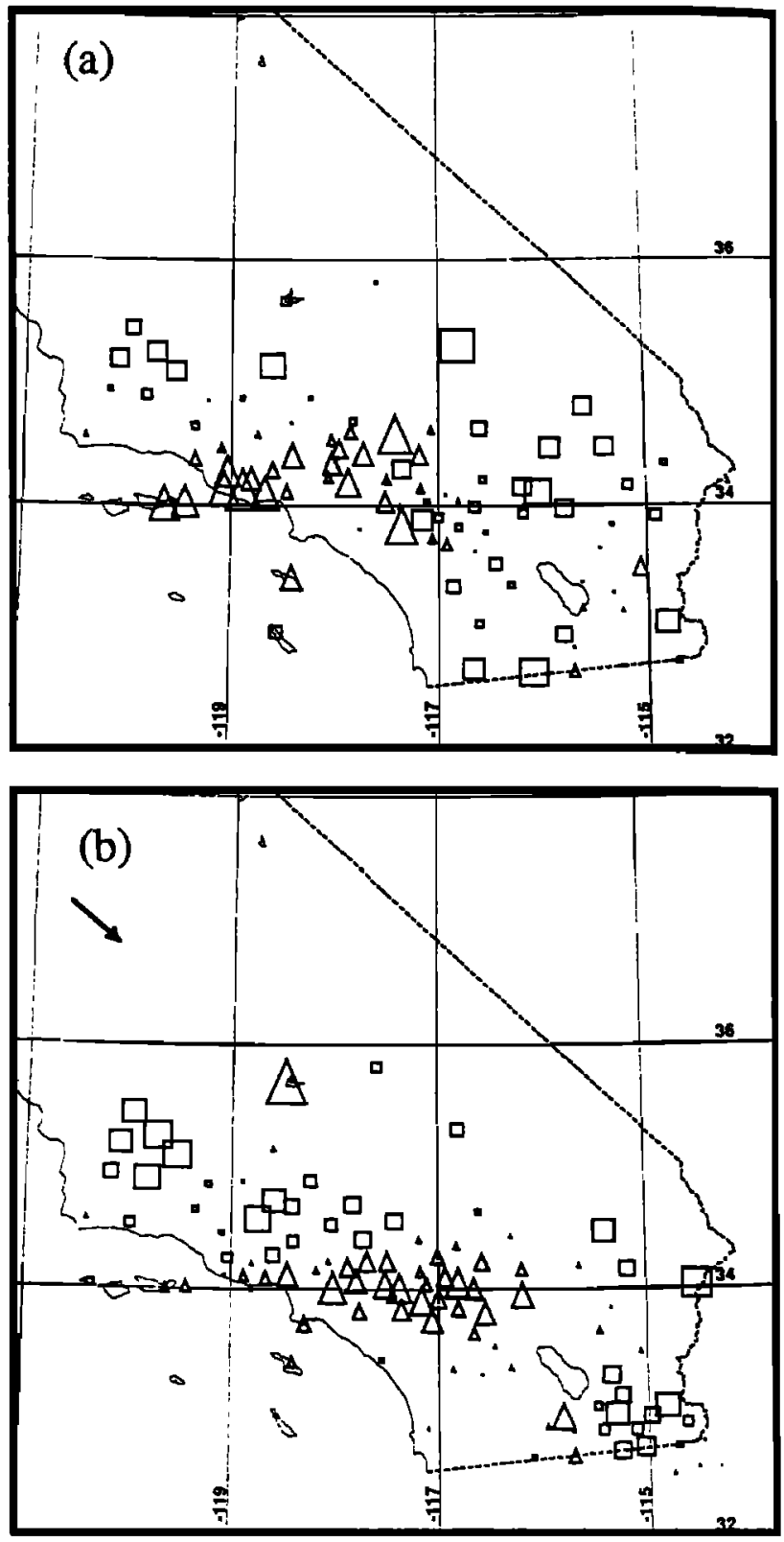

Fig. 4. Maps of travel time residuals for two well-recorded events. The triangles represent early arrivals, and the squares represent late arrivals. Symbol size is proportional to delay value For reference, the earliest arrival in the upper map is $0.68 \mathrm{~s}$ early, while the latest arrival is $0.65 \mathrm{~s}$ late. (a) Delays from a nearly antipodal event, indicating the integrated slowness directly beneath each station. (b) Delays from a Korean event $\left(\Delta=82^{\circ}\right.$; azimuth of approach indicated with arrow), with the delay pattem shifted to the $S E$.

blocks that best account for observations are determined. (See, for example, Aki et al. [1977] for a discussion that is particularly relevant to teleseismic ray geometry.) Because all rays traverse the entire model thickness, we camnot address the vertical variations in average structure with this ray geometry. For instance, because an infinite, uniform horizontal slab will have the same travel time effect on all teleseismic arrivals, we have no information on its depth.

We have made use of several approximations that simplify the computations. Because the data set is composed of rays that are all within $45^{\circ}$ of vertical, a ray may be assigned to one and 
only one block per layer of blocks without significant loss of wocuracy. If a ray happens to pass through more than one block in a layer, the ray is assigned to the block with the longest ray segment. The assumption that a ray traverses the entire layer within a single block greatly reduces the number of geometrical factors that need to be determined. Once ray segments are assumed to traverse only one block per layer, all ray lengths within any block become approximately equal, and the basic backprojection equation, $s_{b}=\sum_{r} d_{r} l_{r b} / \sum_{r} l_{b}^{2}$ [Humphreys and Clayton 1988], can be simplified without perceptible alteration of the inverse to $s_{b}=\sum_{r} d_{r} / \sum_{r} l_{r b}$, where $s_{b}$ is the slowness estimate of the $b$ th block, $d_{r}$ the delay of the rth ray, and $l_{r b}$ the length of the rth ray in the $b$ th block.

Various algorithms are used in conjunction with basic backprojection to invert the data. Humphreys and Clayton [1988] discuss the general principles underlying these algorithms. The specific set of algorithms chosen here includes iteration, block subbinning, filtering by wave number domain deconvolution, and spatial averaging. Other combinations of techniques are also possible. We have tried various combinations, and they have yielded inverses essentially equivalent to those presented below.

\section{Iteration}

A single backprojection produces a blurred, low-amplinde image. To sharpen the image, iteration is commonly applied by backprojecting the difference between observed delays and those predicted by the latest inverse to obtain an updated inverse. This update is then added to the latest inverse to obtain a new estimate of the slowness structure. The reconstructions shown in Figures 9-15 are created with five iterations.

One could incorporate a ray tracing procedure to recalculate ray trajectories between iterations, but this is not done here. Rather, we trace the rays through the simple vertical structure shown in Figure 5. This procedure is justified when slowness variations are small, because changes in ray position resulting from these variations have only a second-order effect on travel time [e.g., Aki et al., 1977]. Mislocation of ray paths owing to a backprojection through our assumed and somewhat inaccurate structure also affects our ability to produce a sharp image, and unlike the effect on travel time, ray position can be sensitive to slowness structure. However, because we believe slowness variations beneath southem California attain values of only a few percent, we do not expect problems associated with structural heterogeneity to influence ray position or travel time strongly. But because ray position becomes less certain away from the Earth's surface (where stations are located and ray positions are known), the ability to locate rays, and therefore resolution, diminishes with depth.

\section{Block Subbinning}

Arrivals from the NW and the SE dominate the teleseismic ray set used in this study. The resulting images tend to blur along paths associated with these rays. To partly compensate for this problem, we employ a scheme that reduces the weights of those rays traversing the structure in the most common directions. The procedure involves dividing the set of rays which hit any particular block into subbins, according to ray parameter and back azimuth, as indicated by the template in Figure $6 a$.

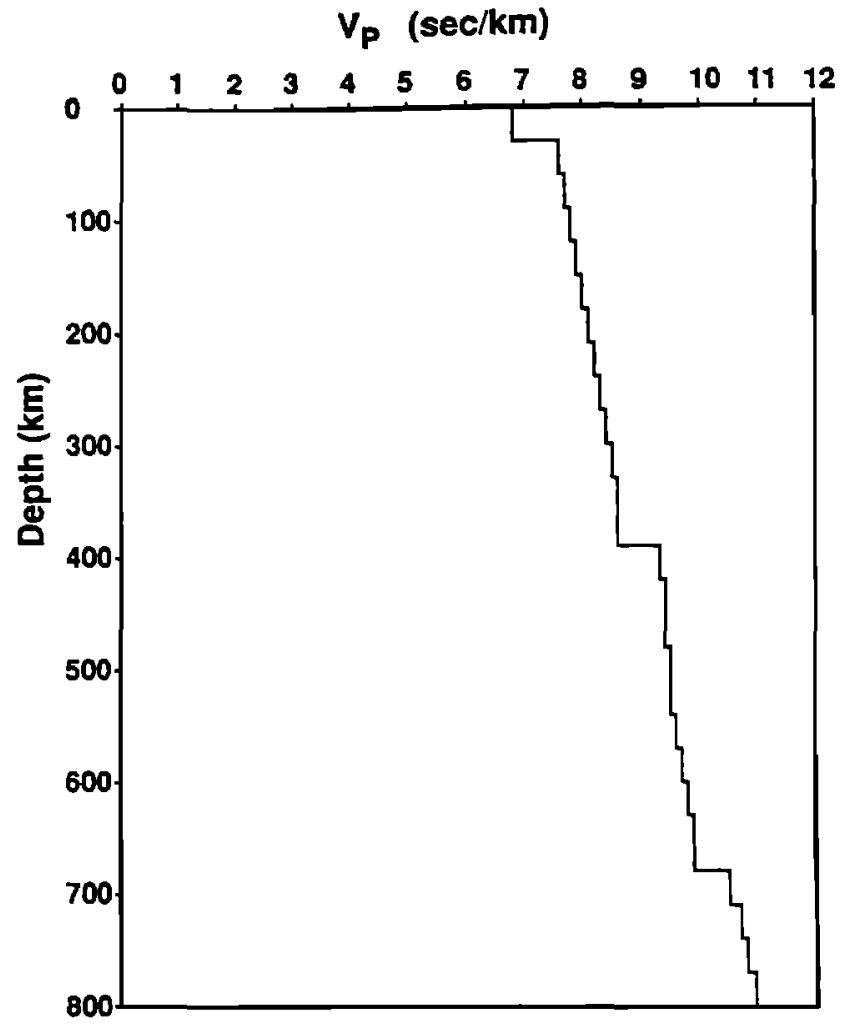

Fig. 5. The one-dimensional $P$ wave velocity structure used to guide ray paths. This structure is a discretized representation of the structure determined for the Gulf of California by Walck [1984]. The only use made of this structure is in determining ray paths, and because the ray paths are nearly vertical, the exact nature of this structure is not critical.

This template takes advantage of the fact that most rays arrive from the NW and SE.

A slowness determination is made for each of the subbins, and these determinations are then averaged to obtain an estimate of the whole block slowness. The average is calculated for each subbin using the weighting function shown in Figure $6 b$. This function increases the net weight of those subbins more frequently hit, while it decreases the importance of the individual rays that fall within the often hit subbins. The number of hits per subbin ranges from zero to more than 100 , with a median value of 3 . Because this subbinning algorithm tends to average delay values over ray parameter and back azimuth, it has the desirable effect of reducing errors that might arise if the ray set samples anisotropic velocity structure.

Average subbin weights of a block also can describe in a simple numerical manner the overall ray coverage of a block, or "hit quality." As a result of our subbinning algorithm, both the quantity of rays hitting a block and the distribution of rays in back azimuth and in ray parameter are important in determining the hit quality value. Values of hit quality determined this way range in value from zero for an unhit block to unity for a wellhit block. Figure 7 shows plots of hit quality within the inversion domain. Hit quality diminishes in value towards the lateral margins of the inversion domain in general and beneath the Pacific Ocean in particular. It also decreases with depth.

\section{Filtering}

When resolution is not perfect, which is expected with real data, there is a natural tendency for backprojection to blur the 

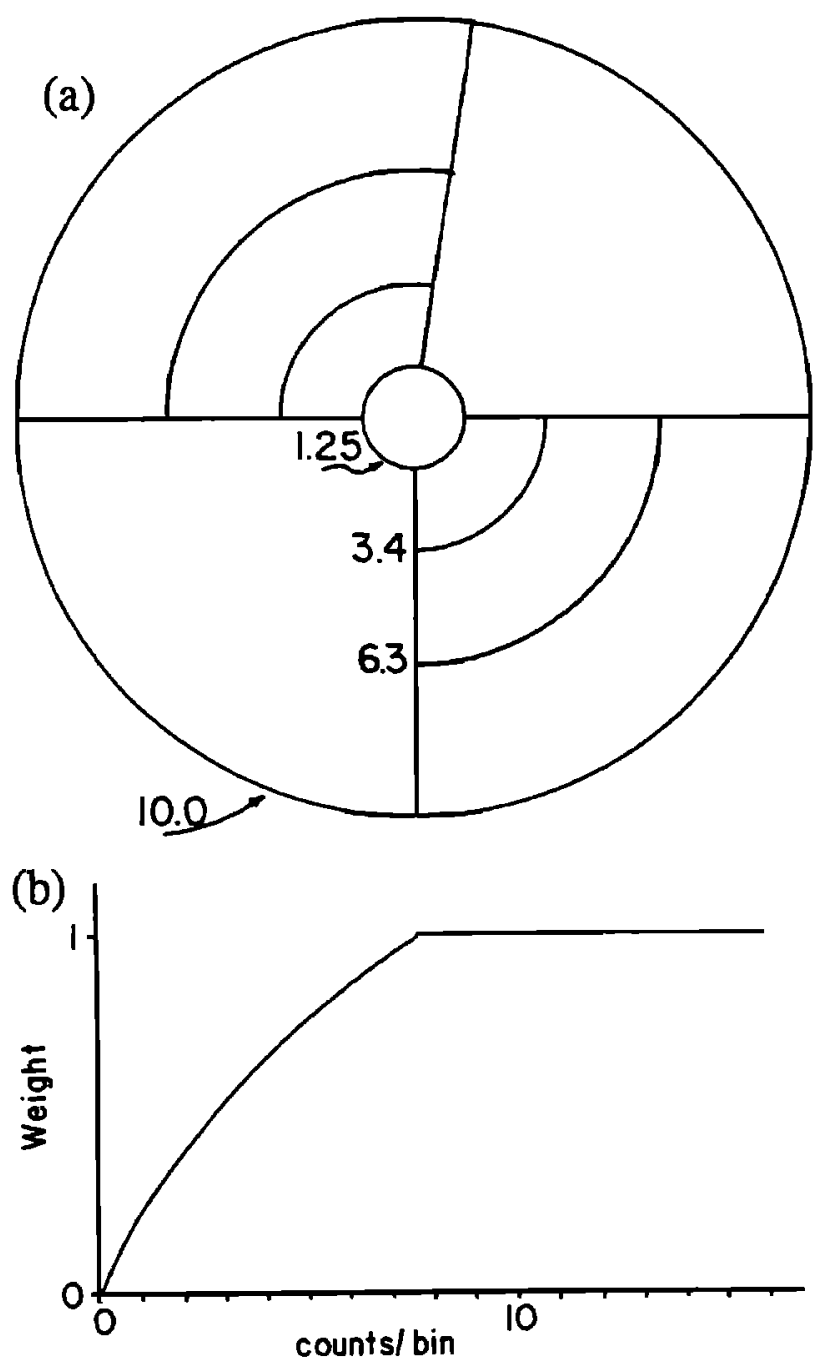

Fig. 6. Figures illustracing the details of the sub-binning scheme used in the tomographic inversion. (a) The nine bins used in back azimuth-ray parameter space. North is to the top and the numbers are in units of s/deg. (b) The weight given each bin (as a function of hit count) prior to averaging to obtain a whole bin slowness estimate. For more discus sion, refer to the text.

image in the direction taken most commonly by the rays. In our case, this is the vertical direction. A block's "point-spread function" is the image resulting from a backprojection of delay times calculated for a model consisting solely of that anomalous block It is analogous to a Green's function. The point-spread function can be used to construct a filter that reduces the backprojection-produced blurring [Humphreys and Clayton, 1988]. Because the inversion of any test structure is simply the linear superposition of point-spread functions, this filter can be applied to the blurred image of an arbitrary structure. If a ray set were homogeneous (resulting in identical point-spread functions from different parts of the inversion), a single filter is globally applicable. However, with our nonhomogeneous ray set, point-spread functions differ in form from one location to the next, and a single filter can not be consuructed. Instead, we construct a representative point-spread function by averaging nine point-spread functions sampled from regularly spaced locations within the inversion domain. Such averaging is warranted if point-spread functions are similar in shape and amplitude, which proves to be the case. Figure 8 shows the average point-spread function. Figure $8 a$ shows the point-spread function produced without the use of subbinning, while Figure $8 b$ shows the effect of including subbinning. Note that the use of sub-binning significantly attenuates the amplitude of the prominent streaks.

In this paper, filtering is implemented through deconvolution by division in the wave number domain with an empirically determined average point-spread function. Because deconvolution can be unstable, we take two steps to insure stability. First we window the point-spread function to include only seven blocks in the vertical dimension and nine blocks in the two horizontal dimensions. The windowed portion of the point-spread function also is tapered to zero near the window boundaries, thereby minimizing truncation effects. Second, we clamp (i.e., prevent from falling below a specified level) the wave number domain representation of the windowed point-spread function, so that its transform coefficient amplitudes never drop below the RMS value of the set of transform coefficients.

\section{Spatial Averaging}

In most parts of the model ray coverage is not adequate to warrant the use of blocks as small as we choose: $15 \mathrm{~km}$ by 15 $\mathrm{km}$ and $30 \mathrm{~km}$ deep. Accordingly, we apply a horizontal spatial smoothing after each iteration. This is done with a moving average by using a window the extent of which varies in inverse proportion to the hit quality estimate of each block (Figure 7). We do not apply vertical averaging because the point-spread function already is vertically elongated and therefore naturally smooths in this direction.

Each well-hit block (based on our experience, hit quality of greater than 0.40 ) is averaged only with its four nearest horizontal neighbors. The sum of the weights of the neighbor blocks is chosen to equal the weight given the central block; i.e., the central block is assigned a weight of one-half, and the neighbor blocks are assigned a weight of one-eighth each. Blocks of fair hit quality (between 0.18 and 0.40 ) are averaged not only with the four nearest neighbors but also with the eight next nearest horizontal neighbors. In this case, each set of neighboring blocks is assigned a net weight of one third, as is the central block. For blocks of poor hit quality (between 0.05 and 0.18 ), the next-nearest eight blocks beyond the first two sets also are included in the average; each group of blocks is then given a net weight of one quarter. Using this windowing algorithm, therefore, averages the model over a range of $15-35 \mathrm{~km}$ from the central block. No inverse is determined for blocks with hit quality less than 0.05 .

During averaging, we also use the hit quality estimate to assign relative weight differences to individual blocks. By averaging in this way we do not distort the inverse; the weighted combination of several smaller blocks into a few larger blocks gives the same result for each iteration as would be obtained if the inversion were run originally with the larger blocks.

\section{RESOLUTION AND ERROR}

The most direct means of testing the resolution of an inversion is to first calculate the set of travel time delays that result from tracing the actual ray set through a synthetic test structure, then invert those delays as though they were data, and finally compare the synthetic inversion with the initial structure. This 

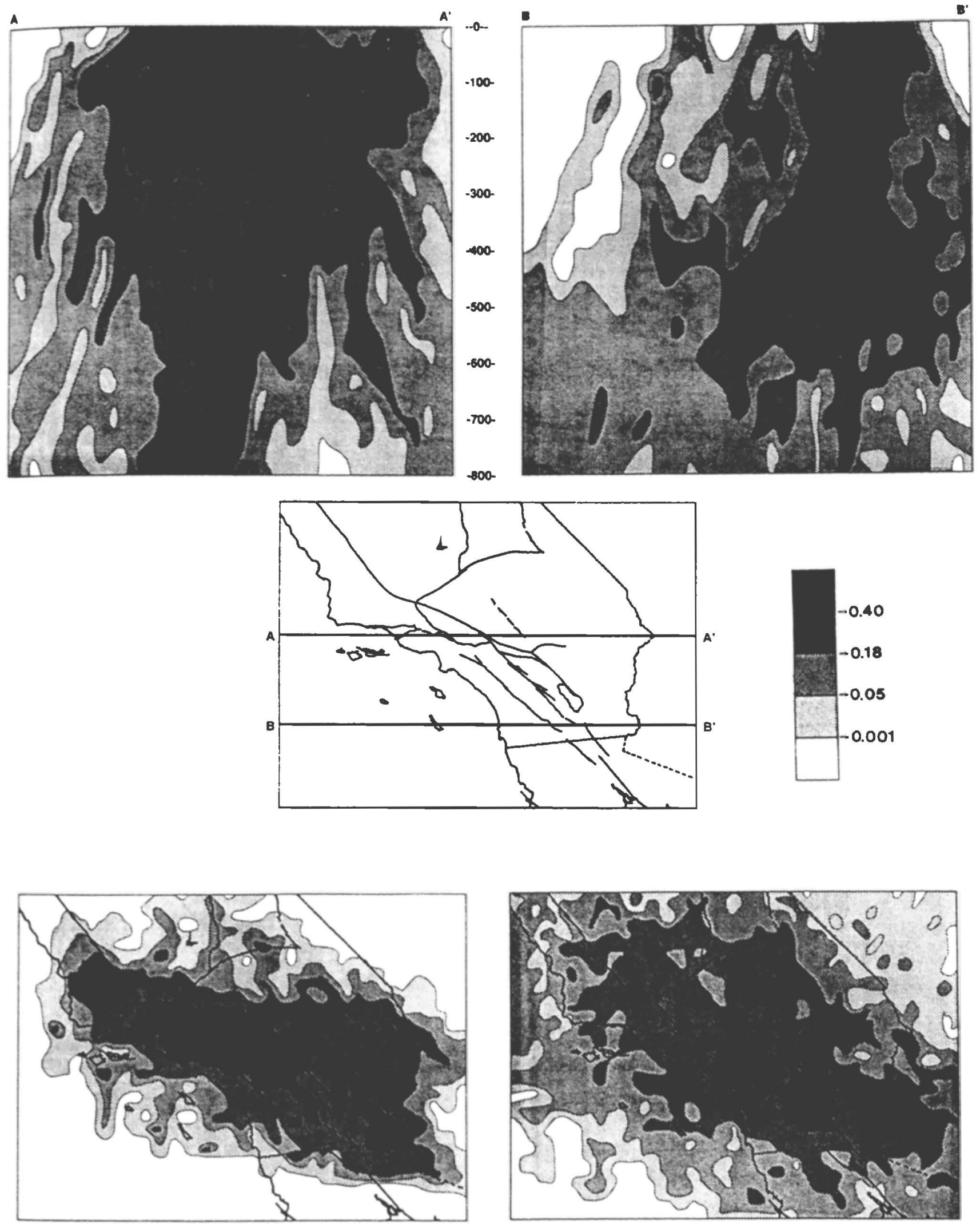

$20-120 \mathrm{~km}$

$360-390 \mathrm{~km}$

Fig. 7. Views of the "hit quality" factor (discussed in the text). Hit quality is a measure of the geometrical variety and number of rays that hit a block and is determined by tracing rays down from the stations shown in Figure 3 , through the structure shown in Figure 5, and according to the ray information given in Figure 2. An ideally hit block will have the maximal hit quality factor of one, while an unhit block will have a value of zero. Practically speaking, a hit quality factor of over 0.18 has been found to indicate sufficient ray coverage to resolve most structures. 


$$
\frac{k \mid}{k}
$$


approach offers a means of carefully testing how well an inversion resolves arbitrary structure. Below we discuss two cases that exemplify the ability of our inversion to reconstruct structures of various geometry. In the Results section we discuss tests of synthetic structures similar in form to those actually found by inverting the real data. Both the ray set and the inversion method employed for the test structures are identical to those for the actual data, except that no smoothing is applied in the test cases.

\section{Single Block}

The simplest test case is that of a single anomalous block. This inversion represents a case of special interest; when the geometry of rays sampling most blocks is similar (as in this study). such an inversion is essentially the resolution kernel for the block [Humphreys and Clayton, 1988]. Figure 9 illustrates the reconstruction of a test block located in the well-sampled central portion of the model. Resolution is very good, and the reconstruction exhibits great improvement compared to the point responses under a single backprojection (Figure 8). The amount of artificially produced anomaly is very small, even in blocks neighboring the anomalous block, and the anomalous block is $66 \%$ of its original value. The inversion accounts for $99 \%$ of the variance of the synthetic data (i.e., $92 \%$ of the RMS of the residuals is explained).

\section{Large Cube With Nonanomalous Interior}

Figure 10 illustrates the reconstruction of a structure difficult to resolve: an anomalous cube with a nonanomalous interior. This structure consists of thin slabs oriented both vertically and horizontally, and a large nonanomalous region sampled only by rays that elsewhere have sampled anomalous material. The results clearly show capabilities and difficulties inherent with the available ray geometry. The horizontally oriented structures are poorly resolved: the top is diffuse and distributed over several layers, and the bottom is even less focused. This contrasts with the well-reconstructed vertical walls, where the amplitude attains $80 \%$ of the original value. The inversion accounts for $99 \%$ of the variance of the synthetic data (i.e., $91 \%$ of the RMS of the residuals is explained).

\section{Noise Sensitivity}

With the least squares inverse, the effect of noise on an inverse is commonly addressed by examining the covariance of the slowness estimates through the relation

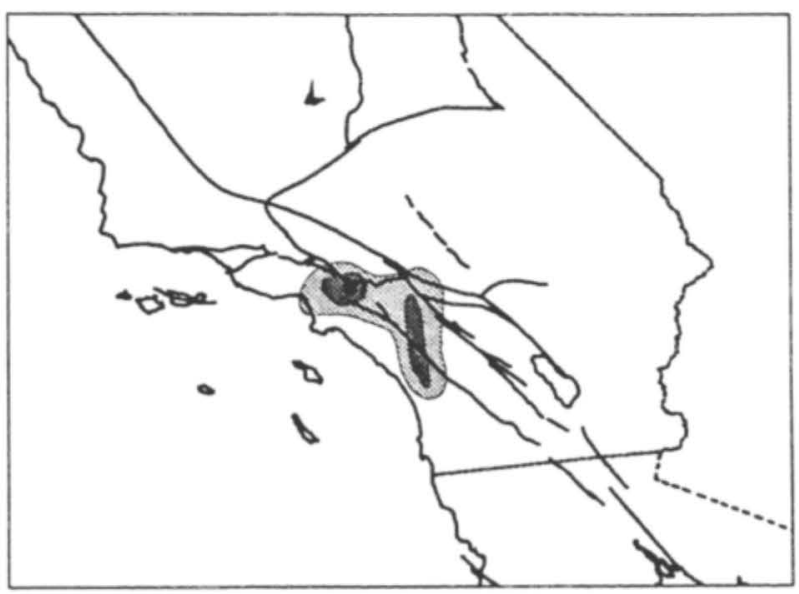

$180-210 \mathrm{~km}$

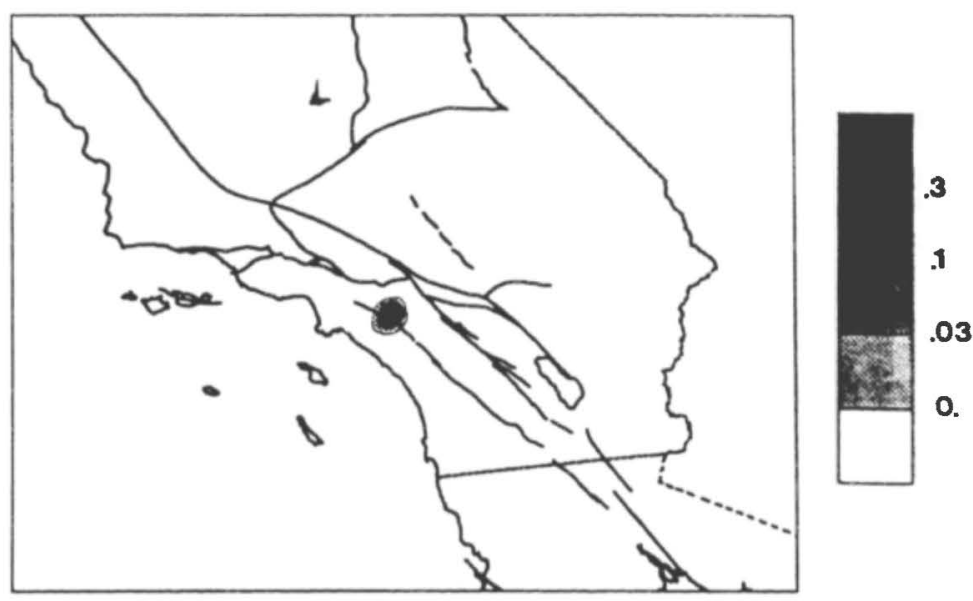

$270-300 \mathrm{~km}$

Fig. 9. The reconstruction of a single anomalous block of unit magnitude with the use of subbinning, deconvolution, and five iterations. The lowest horizon passes through the anomalous block, and the upper horizon is three layers above the block. About two-thirds of the ancmaly is located in the central block. The reconstruction is essentially equivalent 10 the resolution kemel for this block. 

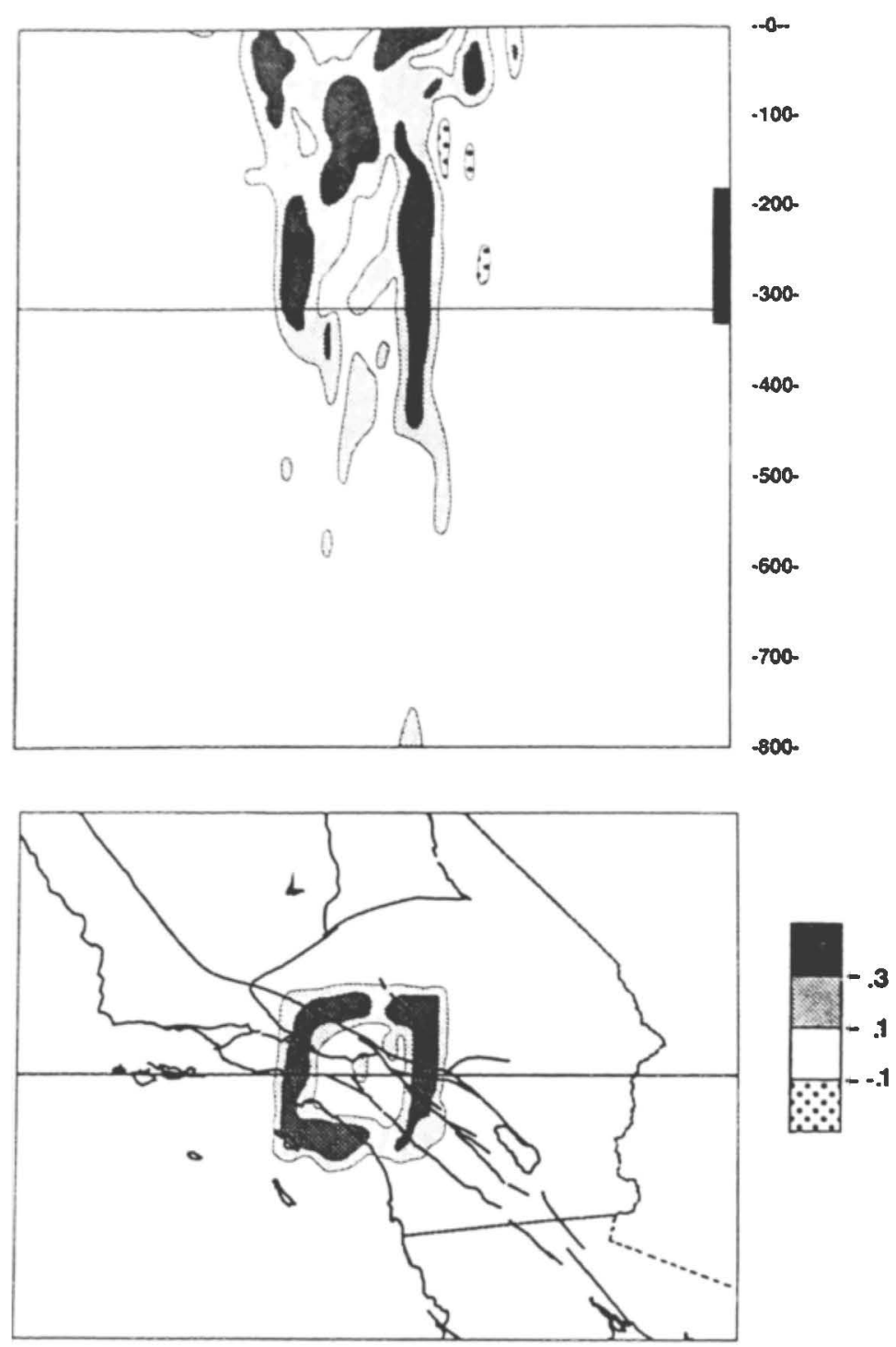

Fig. 10. The reconstruction of an anomalous cube with a nonanomalous interior. The magnitude of the input anomalous structure is unity. The inversion procedure includes subbinning, deconvolution, and five iterations. The inversion has reconstructed the four walls fairly well, but the top is poorly focused and the botom is nearly absent. This is a result of using only rays that traverse the structure in a near-vertical direction, making horizontal structure difficult to resolve.

$\operatorname{Cov}(s)=s s^{T}=\sigma^{2}\left(L^{T} L\right)^{-1}$. $L$, the ray length matrix containing the values $l_{\text {rb }}$, obeys the travel time relation $L s=d$, where $s$ and d are the slowness model vector and delay time vector, respectively. The model covariance relation holds when all estimated variances $\sigma_{i}^{2}$ are independent and each equal to some constant variance estimate $\sigma^{2}$. We expect the southem California data to meet these criteria; we believe the errors associated with the data are very small because our ability to pick the arrival times is good, usually within $\pm 0.05 \mathrm{~s}$. Larger sources of error result from approximating the structure as a spatially confined array of constant velocity blocks. For instance, travel time residuals will differ between two vertical rays that sample the same set of blocks because different rays sample along different paths and are influenced by structure smaller than the block size. Also, significant amounts of delay may occur before a ray enters the region modeled. Estimating travel time error resulting from these sources a priori is difficult, but each ray is as likely to be affected as any other, and the set of errors should be random.
However, because we do not construct $\left(\mathrm{L}^{\mathrm{T}} \mathrm{L}\right)^{-1}$ and therefore do not know $\mathrm{ss}^{\mathrm{T}}$, we cannot use the model covariance matrix to quantify the effects of noise. Instead, we invert a set of random time delays in the same way we invert the actual data, and we examine the resulting inversion. Although this procedure lacks the ability to identify explicitly the eigenvectors of $\mathbf{L}^{\mathbf{T}} \mathbf{L}$ responsible for particular instabilities, it does test the overall sensitivity of the inverse to noise. We use a zero-mean Gaussian distribution as the time delays (i.e., as the "data"), and we construct the synthetic set of delays to possess the same variance as the actual data. To be consistent with the real data, we exclude very anomalous delays by removing delays of value greater than three standard deviations. Figure 11 shows an inversion. The resulting structure is not coherent, is very low in amplitude, and accounts for only $15 \%$ of the variance of the random delays used as data (2.2\% of the RMS of the random delays). As the synthetic examples demonstrate, virually all of the signal is accounted for when synthetic delays are generated with coherent 


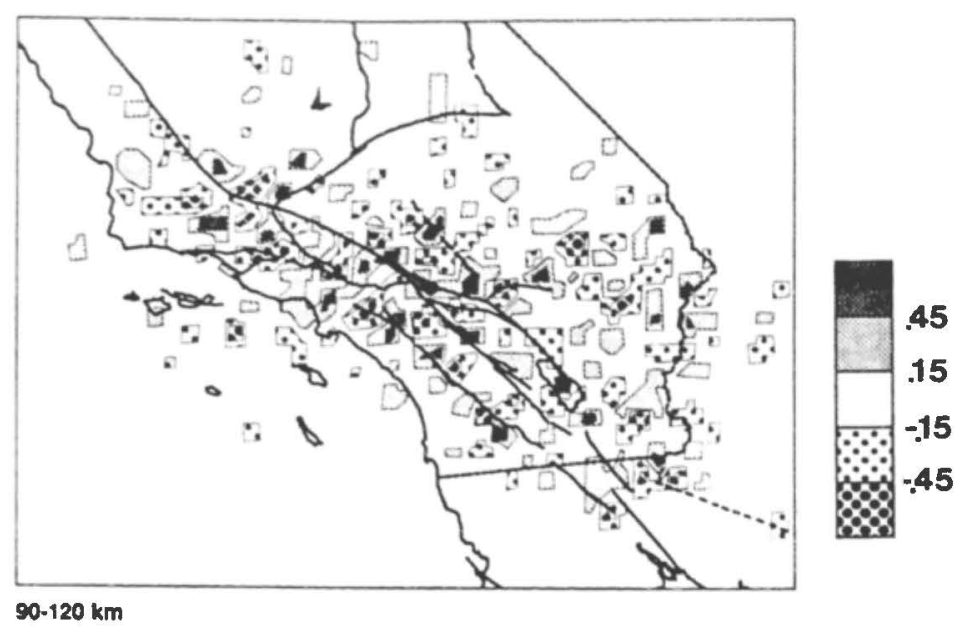

Fig. 11. The inversion using random noise travel time residuals. The procedure includes subbinning, deconvolution, and five iterations. Values are in percent of RMS of the inputted noise divided by the block height. (If the contoured values are thought of as \% velocity, then the input delays are greater than the das by a factor of about 3 in an RMS sense.) The low values of reconstructed anomaly attest to a general insensitivity of the inversion to random noise.

structure. Because the expected level of noise in the actual data is small, we do not anticipate noise-related artifacts in the inversion of actual data to present a major problem.

\section{RESULTS}

The inversion of the actual travel time delays is illustrated in Figure 12. Figure $12 a$ shows results presented by Humphreys et al. [1984], where relatively large blocks were used, and Figure $12 b$ shows results using the smaller blocks discussed above. The larger-block inversion is essentially a smoothed version of the smaller-block inversion. The structure shown in Figure $12 a$ accounts for $76 \%$ of the variance (or $51 \%$ of the RMS) of the reduced data, while the structure shown in Figure $12 b$ accounts for $85 \%$ of the variance (or $62 \%$ of the RMS) of the reduced data. Two principal fearures are resolved, a high-velocity anomaly beneath the Transverse Ranges and a low-velocity anomaly beneath the Salton Trough region.

Resolution tests (such as shown in Figure 9) demonstrate that the central portion of the model has sufficient ray coverage to resolve structure as fine as the block size used. Approximate resolution ability is reflected in the hit quality map (Figure 7), and the central part of the inversion is seen to lie in a wellsampled region. Within this region we find the most prominent feature of the inversion: a curtainlike, east trending anomaly beneath the Transverse Ranges. This anomaly is approximately wedge-shaped, deepest to the east where it extends to a depth of $-250 \mathrm{~km}$ and is $-3 \%$ fast at its center. Average anomaly thickness is $-60 \mathrm{~km}$. While resolution tests indicate that structure in this region should be well resolved, the fact that the map view position of the Transverse Ranges anomaly is very similar to the physiographic Transverse Ranges (see Figure 1) suggests that the image of the Transverse Ranges upper mantle anomaly might be artificially created. However, this correlation cannot be explained simply as a projection of surface or near-surface information to depth, because the information upon which the anomaly is based often does not coincide with the Transverse Ranges. For example, Figure $4 b$ shows that stations well to the south and east of the actual Transverse Ranges record early arrivals associated with the anomaly. Furthermore, any travel time errors arising from the near-surface would resolve themselves principally as features within the uppermost layer. But, as shown in Figure 12 and discussed below, the seismic structure of the crustal layer lacks similarity to the Transverse Ranges physiography, Moho topography, and deeper seismic structure. Also roughly similar in distribution are the Transverse Ranges anomaly and the hit quality. Upon examination, however, many features are found that are not in common, and thus we believe the anomaly is not an artifact of hit quality variations.

The most anomalous low velocities in the inversion, with values exceeding $4 \%$ slow, appear beneath the Salton Trough, the northemmost expression of Gulf of Califomia rifting. We expect low velocities to result from Gulf of California rifting and ascent of hot mante into a region previously occupied by cold lithosphere. The volume of low-velocity mantle, however, extends more broadly than does the physiographic expression of the rift valley. It also appears to end near a depth of $90 \mathrm{~km}$.

Figure $12 a$ suggests that not much strong anomaly lies beneath a depth of $-75 \mathrm{~km}$, whereas Figure $12 b$ suggests that the integrated anomaly is strong in the $60-90 \mathrm{~km}$ depth range. Hence we infer that the "base" of the Salton Trough anomaly probably lies somewhere in the vicinity of $75 \mathrm{~km}$, although this estimate is not well constrained. By examining inversions of test structures we find that if the base were above $75 \mathrm{~km}$, the observed anomaly in the $60-90 \mathrm{~km}$ layer of blocks would not be as strong as it is. And if the base were located deeper than $-100 \mathrm{~km}$. Figure $12 a$ would show a strong influence on the 75 $125 \mathrm{~km}$ layer of blocks, which it does not. Thus $75 \mathrm{~km}$ may be a slight underestimate. We therefore choose $80 \mathrm{~km}$ as our best estimate for the base of the Saiton Trough anomaly, although we do not possess the ability to resolve its position accurately between $70 \mathrm{~km}$ and $100 \mathrm{~km}$.

The volume below $-250 \mathrm{~km}$ is relatively featureless, and the structure imaged there may be artificially produced. On the other hand, if an anomaly of modest dimensions does exist at these depths (especially a vertically thin anomaly), it would not be well resolved and thus may not be recognized as an authentic 


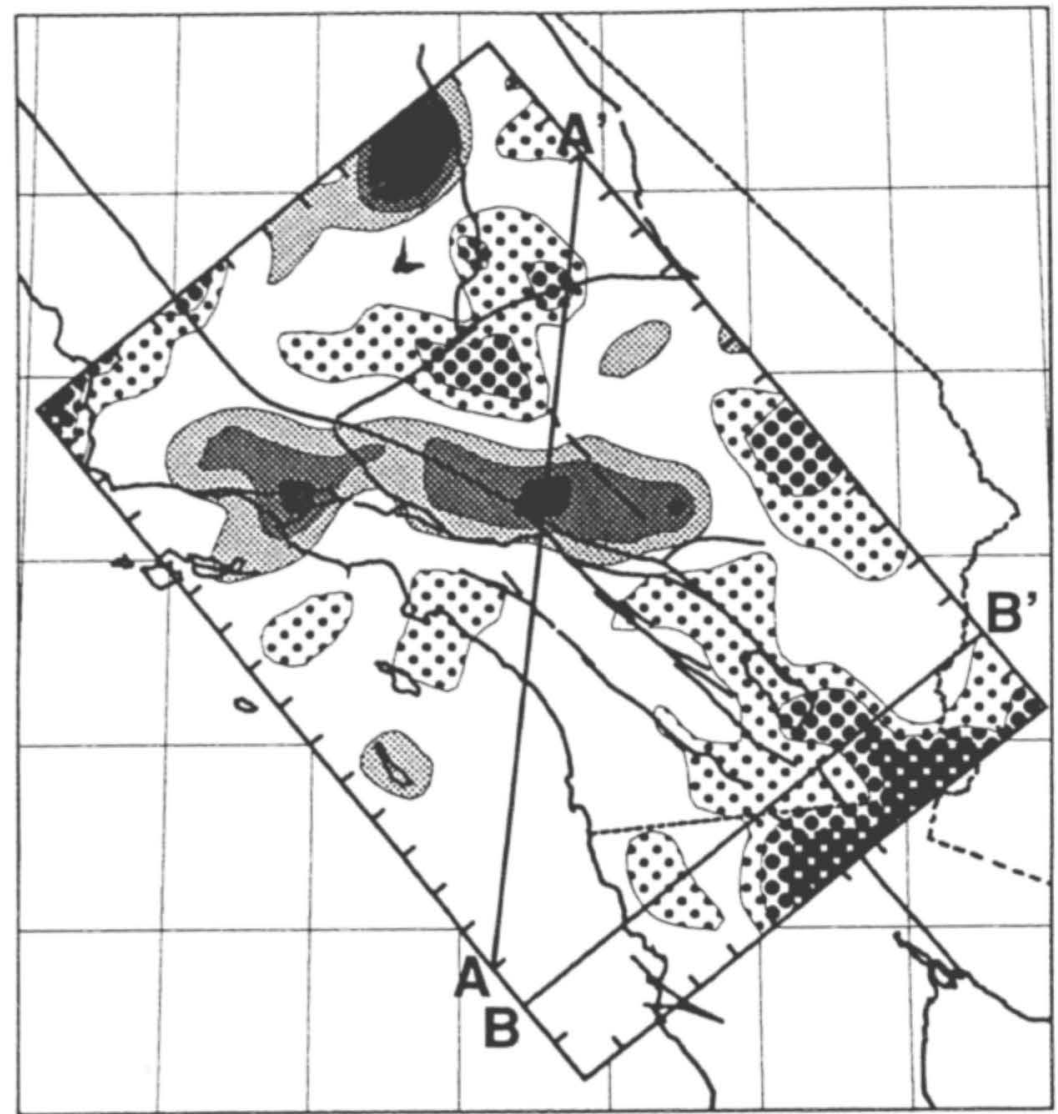

(a)
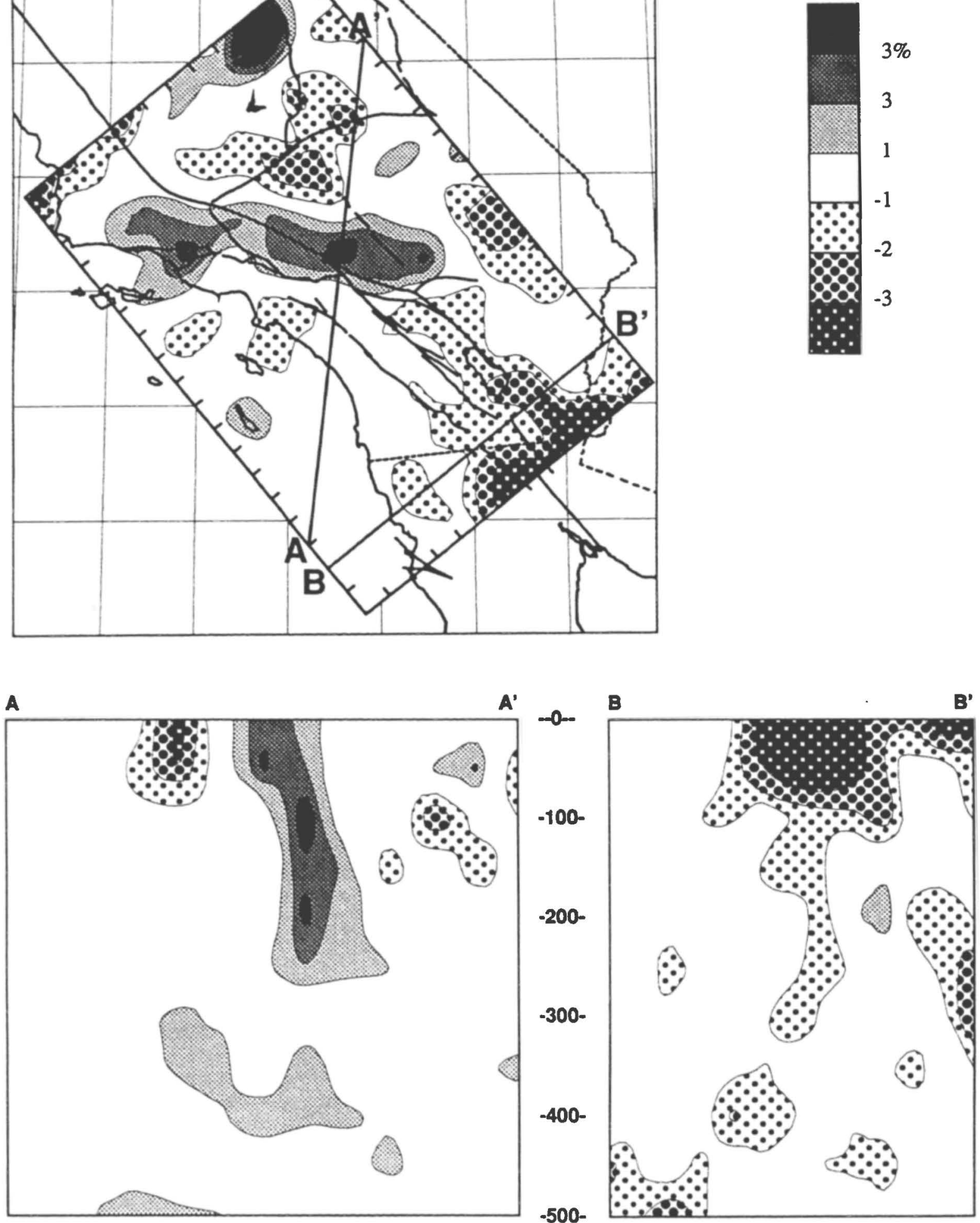

Fig. 12. The inversion of the actual travel time delays with the use of subbinning, deconvalution, and five iterations. The major anomalies seen are the volume of high-velocity material beneath the Transverse Ranges and the region of slow material beneath the Salton Trough. (a) The inversion using relatively large blocks. (b) The inversion with smaller blocks. See text for more discussion. 
(b)
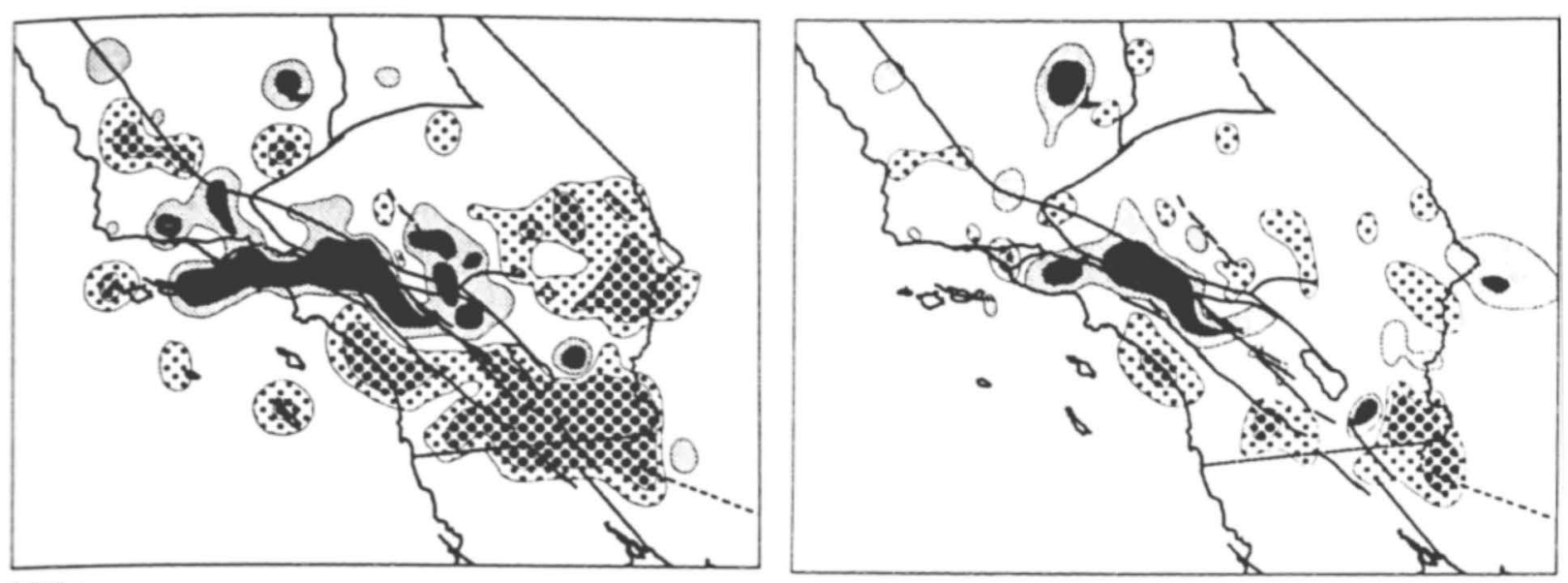

$200 \mathrm{~km}$

$3060 \mathrm{~km}$

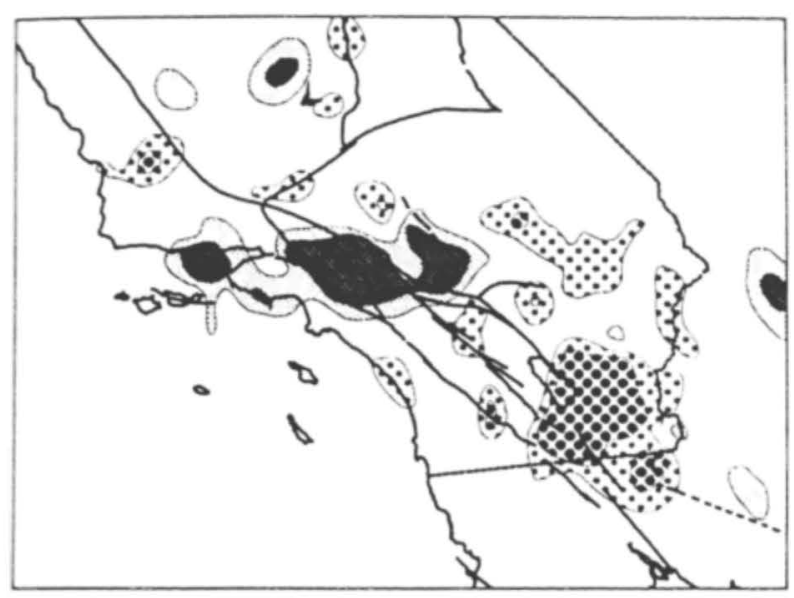

$60-90 \mathrm{~km}$
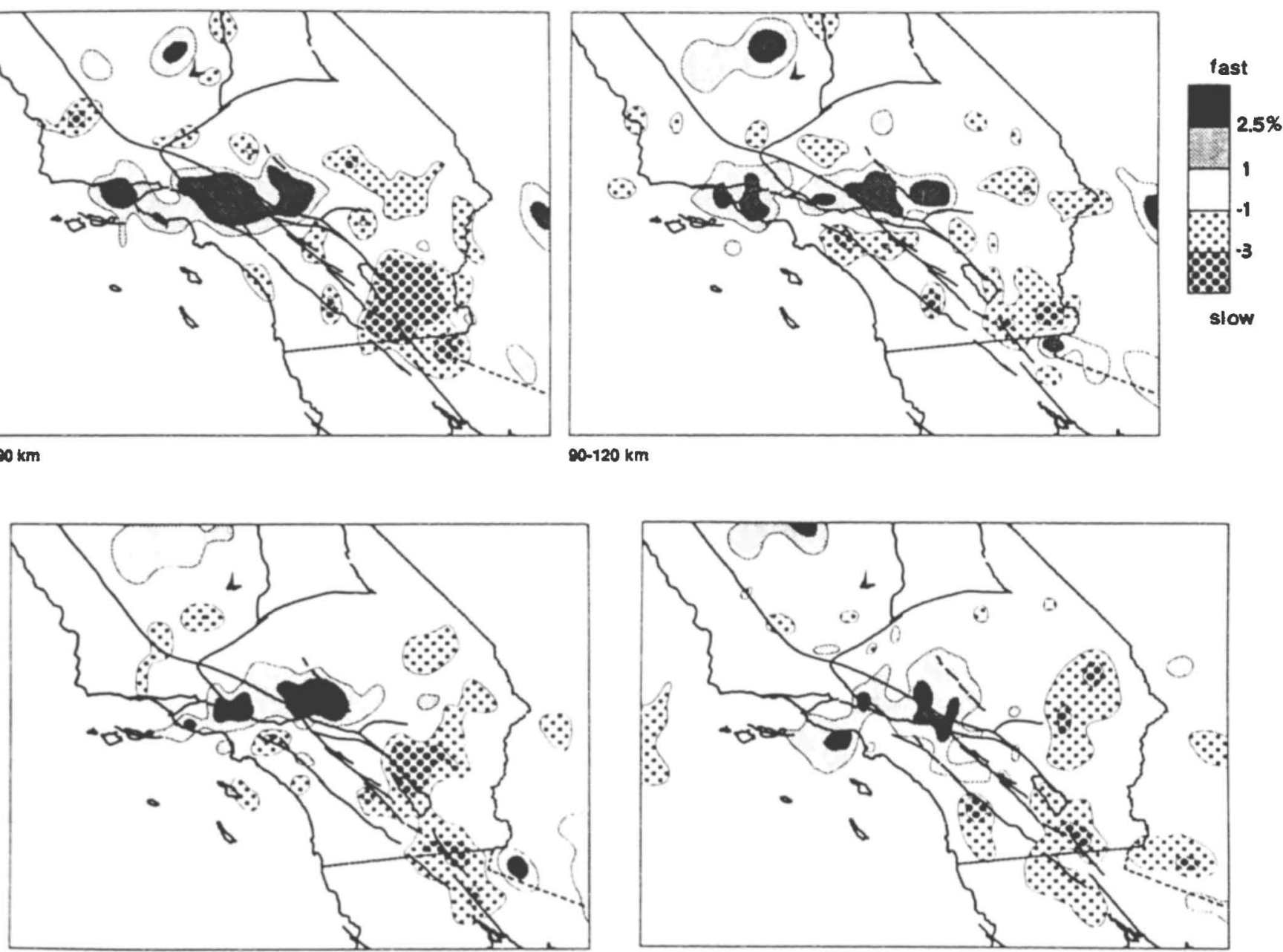

$150-180 \mathrm{~km}$

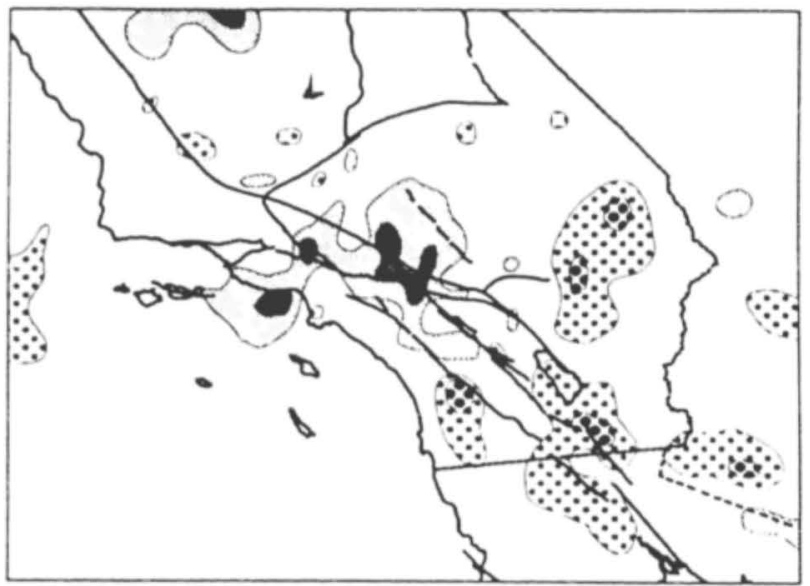

$210-240 \mathrm{~km}$

Fig. 12. (continued) 

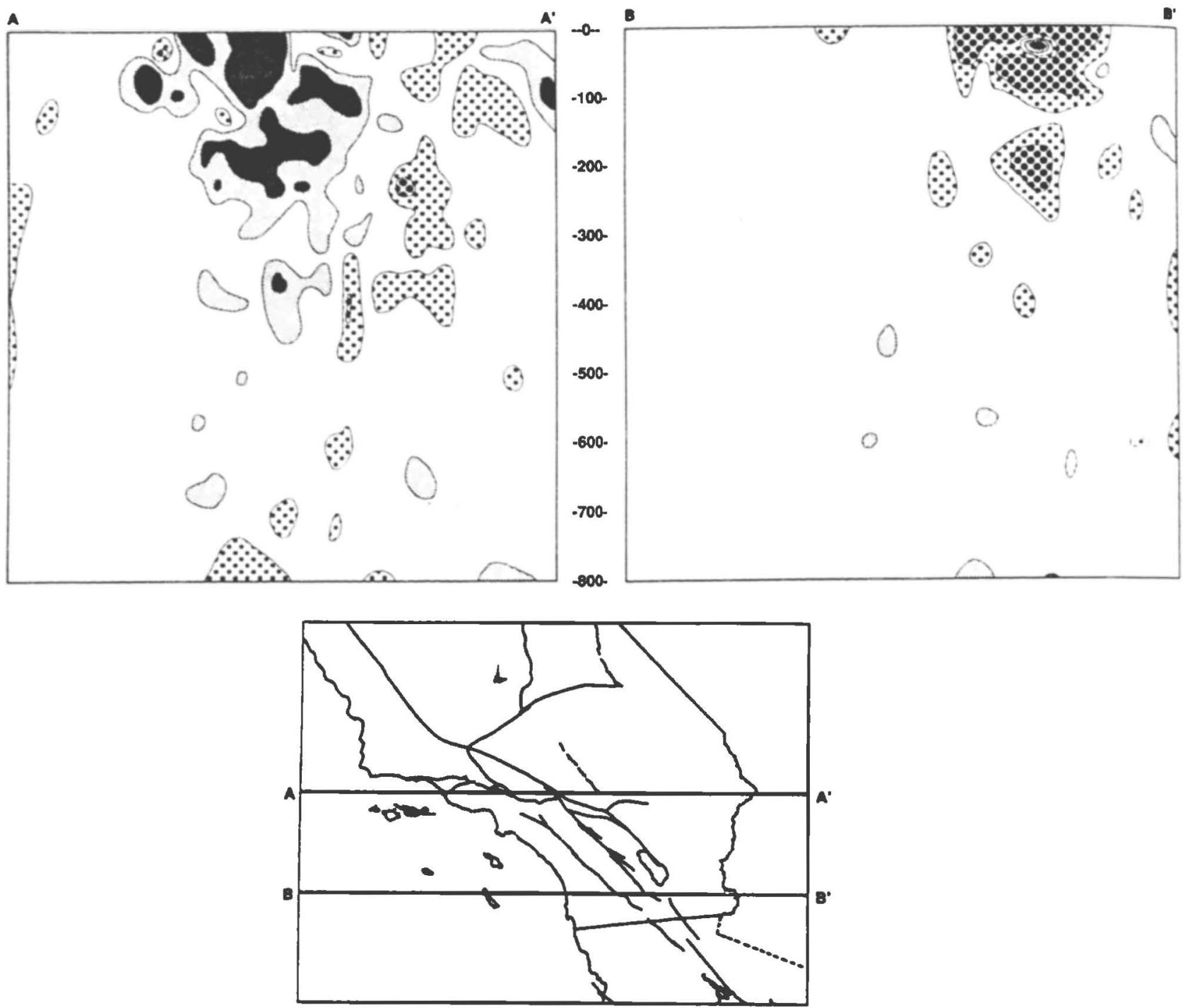

Fig. 12b. (continued)

feature. However, tests indicate that if a major anomaly existed at these depths, its presence would be discovered (though its amplitude may be poorly reconstructed). We find no such features at these depths beneath southem Califomia. Because lateral seismic structure in the Salton Trough region extends no deeper than uppermost mantle (i.e., 70-100 km), we infer that the Salton Trough anomaly is largely a result of seismic velocity contrast between anomalous mantle beneath the Salton Trough region and more typical southern Califomia lithosphere.

\section{Tests of the Inversion}

Simple test examples are constructed to simulate the ability of our method to image structure similar to that imaged beneath southern California (shown in Figures 13-16). These tests are not intended to imply authenticity of the details chosen; they are used simply to gauge our ability at reconstructing detail of this general form. In Figure 13, a thin $(60-\mathrm{km}), 3 \%$ high-velocity, wedge-shaped anomaly is included beneath the Transverse Ranges. It extends to a maximum depth of $300 \mathrm{~km}$ on its east side. Also, to represent the Salton Trough anomaly, the upper three layers $(0-90 \mathrm{~km}$ depth) of the southeast corner are assigned $4 \%$ low velocities. The inversion of the synthetic delays reconstructs the Transverse Ranges structure very well, even for its base. Most of the central portion of the synthetic anomaly is reconstructed to greater than $90 \%$ of its proper value, suggesting that the inversion of the actual data reconstructs the Transverse Ranges anomaly to near its full value.

Figure 13 suggests that modest levels of erroneous structure are included in the $90-250 \mathrm{~km}$ range beneath the Salton Trough as a consequence of the strong anomaly immediately above. The amplitude of structure found beneath the Salton Trough region in the actual inversion is similar to the structure artificially created in Figure 13. This similarity suggests that the low-velocity structures imaged beneath $90 \mathrm{~km}$ may be artifacts and that mantle velocities beneath $-90 \mathrm{~km}$ in the Salton Trough region are not exceptionally slow compared to those of the surrounding mantle.

Hedley and Kanamori [1977] describe the top of a highvelocity "mantle ridge" with an interface $\sim 40 \mathrm{~km}$ beneath the Transverse Ranges. We infer this to be the top of the Transverse Ranges anomaly. The study of Hadley and 

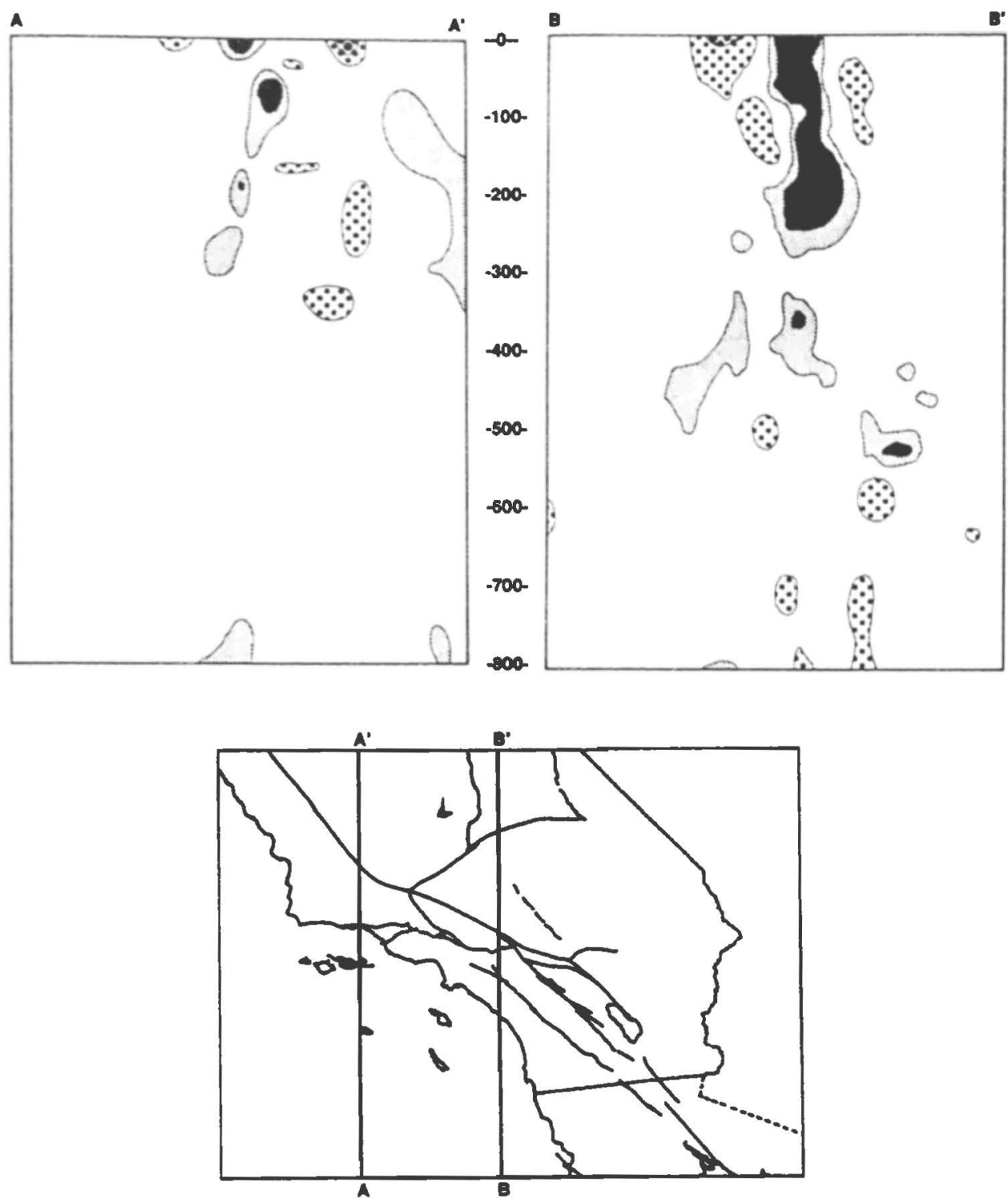

Fig. 12b. (continued)

Kanamori involved regional refraction experiments with welltimed, local blasts, and it offers the best constraint available on the structure of the uppermost mantle in the vicinity of the Transverse Ranges. They estimate the seismic velocity of the mantle ridge to be $-8.3 \mathrm{~km} / \mathrm{s}$, and the velocity of the mantle between the ridge and the Moho to be $\sim 7.8 \mathrm{~km} / \mathrm{s}$. These conclusions are consistent with the findings of Hearn [1984] and Hearn and Clayton [1986b], which indicate $P_{n}$ velocities beneath the Transverse Ranges of $\sim 7.7 \mathrm{~km} / \mathrm{s}$ (as compared to a more typical southern Califomia value of $\sim 8.0 \mathrm{~km} / \mathrm{s}$ ).

To compare these results with our inversion, we average the velocity over the depth range $30-60 \mathrm{~km}$, i.e., over the second layer of blocks. If we average the $7.7-7.8 \mathrm{~km} / \mathrm{s}$ velocity of uppermost mantle beneath the Transverse Ranges with the 8.3 $\mathrm{km} / \mathrm{s}$ velocity of the deeper Transverse Ranges anomaly to determine an average velocity for the interval spanned by the second layer of blocks, we obtain a nonanomalous value of $\sim 8.0$ $\mathrm{km} / \mathrm{s}$ (assuming that the low- and high-velocity mantle is separated at $40 \mathrm{~km}$, as determined by Hadley and Kanamori). We check this prediction against our inversion by modeling a synthetic example identical to that used to create Figure 13, except that here the second layer beneath the Transverse Ranges contains no anomaly. Figure 14 shows the result. At $30-60 \mathrm{~km}$ the amplitude of the anomaly diminishes, but streaking from above and below artificially creates an anomaly within this layer. The magnitude of the artificially created anomaly, however, is markedly lower than magnitudes above and below the second layer. This relationship is similar to that shown for the actual data (Figure 12). Furthermore, Figure 13 demonstrates that reconstructing continuous vertical slab has no tendency to produce artificially a diminished magnitude within the second layer.

The synthetic results suggest the average mantle velocity in the $30-60 \mathrm{~km}$ layer beneath the Transverse Ranges may be nonanomalous or less anomalous than the layers above and below. In addition, the value of $8.3 \mathrm{~km} / \mathrm{s}$ found by Hadley and 


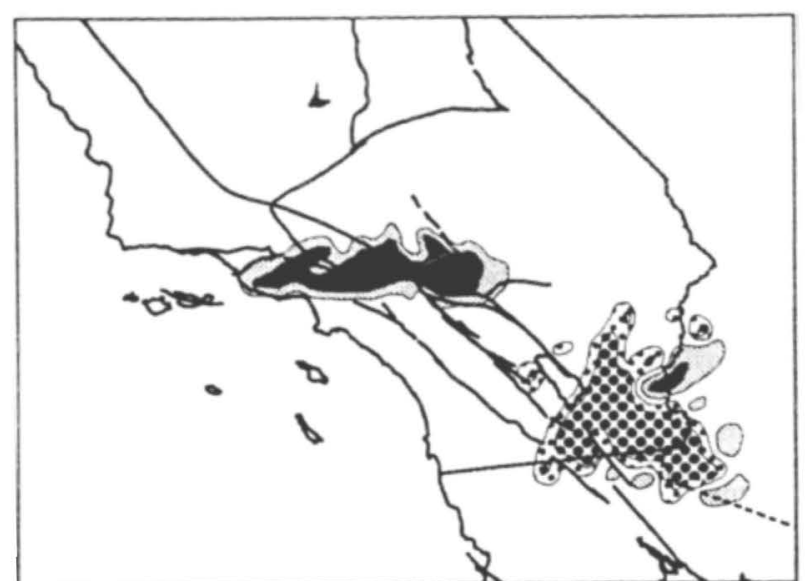

$0-30 \mathrm{~km}$

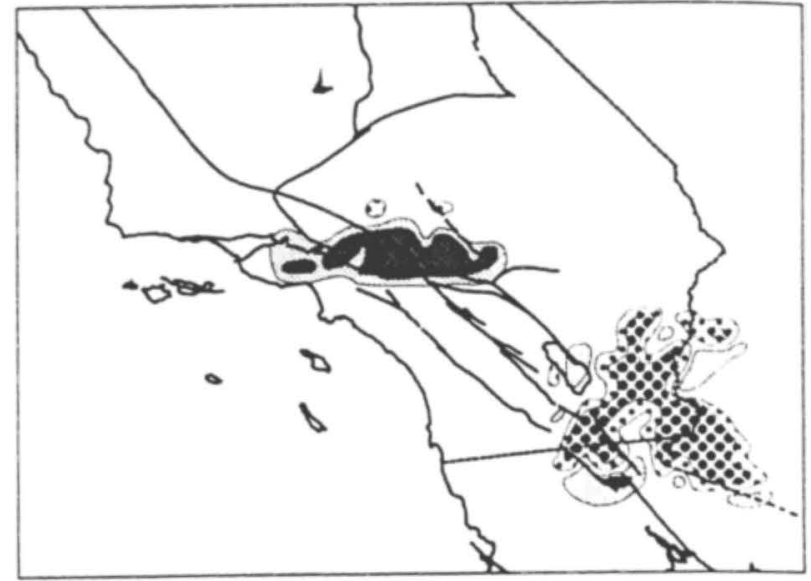

$30-60 \mathrm{~km}$

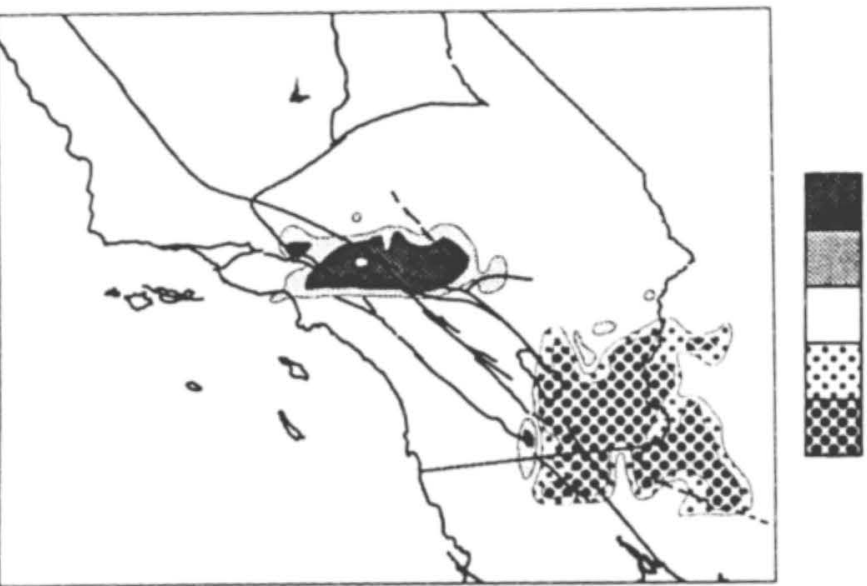

$2.5 \%$

1.0

$-1.0$

$-3.0$

$60.90 \mathrm{~km}$
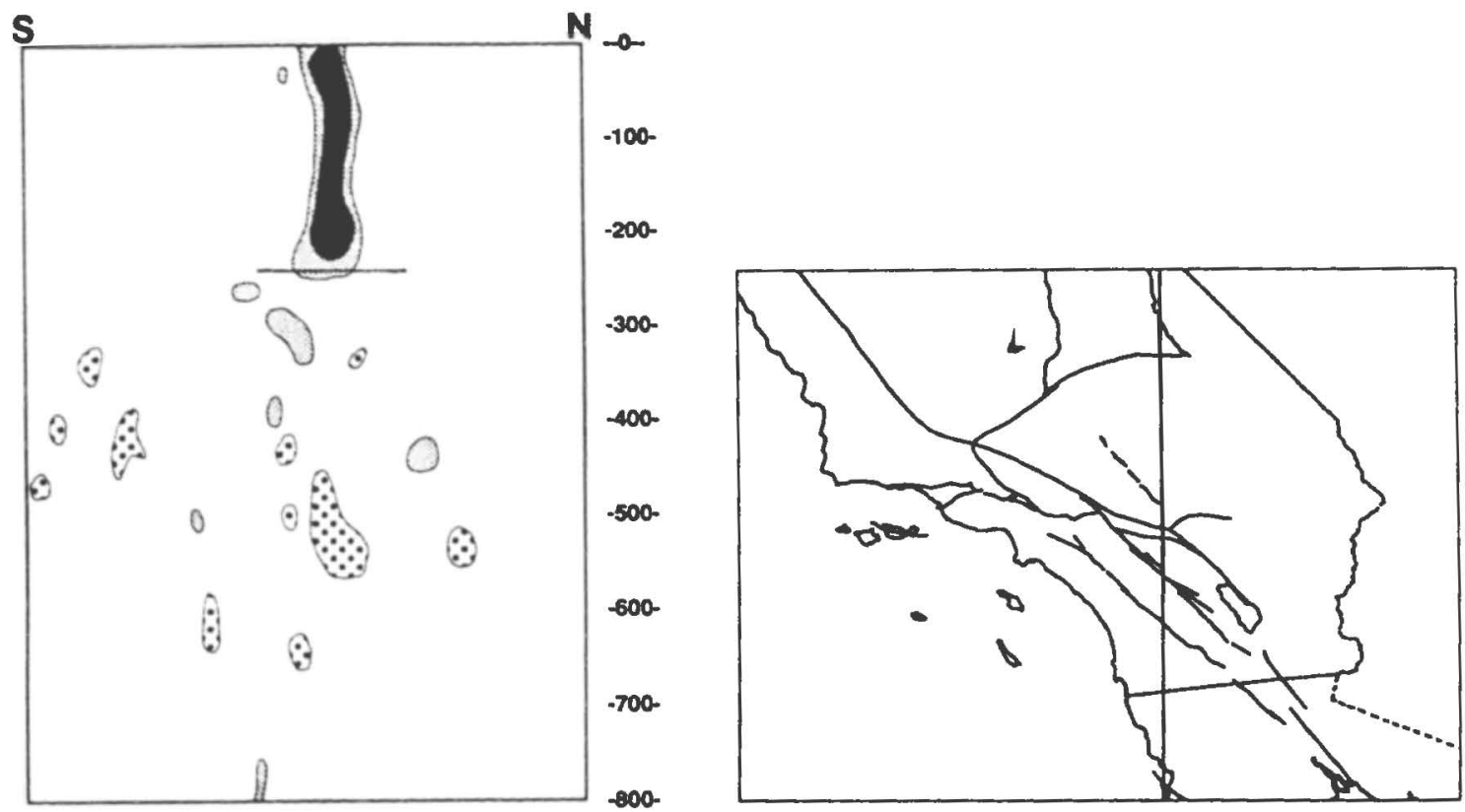

Fig. 13. Inversion of a simple structure designed to simulate the principal features seen in the inversion of the actual delays (Figure 12). Magnitude of the input anomalies are $+3 \%$ ("Transverse Ranges" anomaly) and $-4 \%$ ("Salton Trough" anomaly). The input Transverse Ranges anomaly is $60 \mathrm{~km}$ wide and triangular in cross section seen from the south, extending in depth to the reference line. The input Salton Trough anomaly lies above $90 \mathrm{~km}$. As in the case of the actual delays, inversion includes subbinning, deconvolution, and five iterations. Both major anomalies are capable of being resolved. The Transverse Ranges anomaly is very well resolved, and only small amounts of arifact have been created. Imaging is not as good for the Salton Trough anomaly, and significant amounts of deeper anomaly are arificially produced. 

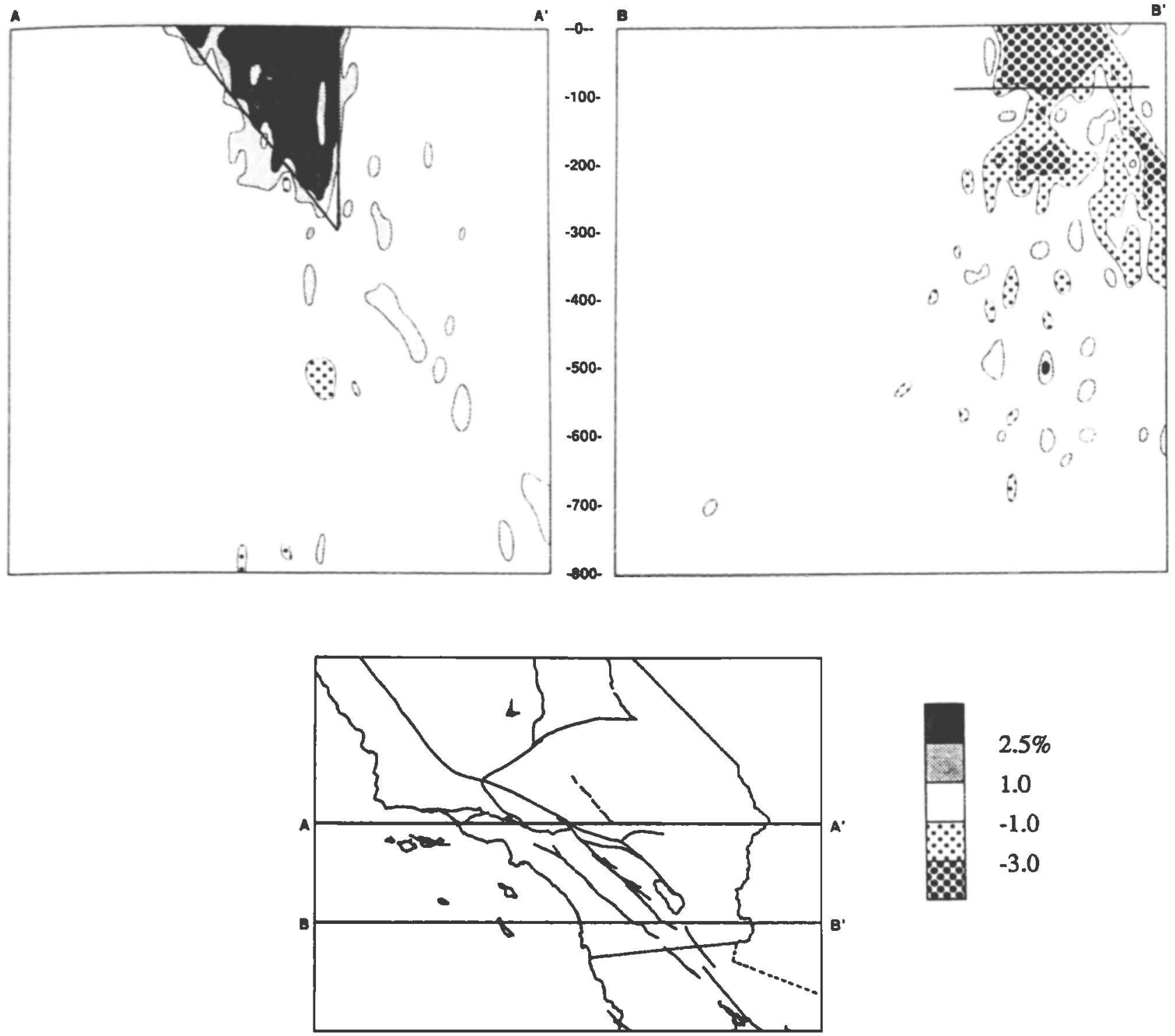

Fig. 13. (continued)

Kanamori for the uppermost portion of the Transverse Ranges anomaly, which is $-3.7 \%$ greater than the typical southem California $P_{n}$ velocity of $-8.0 \mathrm{~km} / \mathrm{s}$, is consistent with our results. Considering both the tendency for the tomographic reconstruction to be slightly undervalued in magnitude and the tendency for spatial averaging to reduce the maximum magnitude, the central portion of the Transverse Ranges anomaly may well approach $4 \%$ in magnitude. Combining the findings of Hadley and Kanamori with our results on the deeper structure, the $-3 \%$ high-velocity anomaly beneath the Transverse Ranges is thought to extend upward from $-250 \mathrm{~km}$ to $-40 \mathrm{~km}$ depth, and the "mantle ridge" of Hadley and Kanamori is attributed to the top of the anomaly.

Figure 12 suggests the Transverse Ranges anomaly is approximately symmetrical in cross section. To test whether this appearance could result from poor resolution of an asymmetrical anomaly, we invert synthetic data corresponding to an asymmetrical Transverse Ranges anomaly. This synthetic anomaly increases linearly from nonanomalous velocities on its south side to velocities $3 \%$ fast on its north side. The results shown in Figure 15 demonstrate that our method can resolve strongly asymmetrical structure, suggesting that the actual Transverse Ranges anomaly is not strongly asymmetric.

In the inversion of the actual data, a high-velocity crustal feature lies $-60 \mathrm{~km}$ south of the mantle Transverse Ranges anomaly (and the physiographic Transverse Ranges themselves) along its eastern end. The effects of this crustal anomaly show up clearly in the antipodal delay map (Figure 4a), where early arrivals appear south of the Transverse Ranges (though this single delay map provides no information on the depth of the anomalous structure). We test the ability of our inversion to resolve this feature (Figure 16) with a simple variation of the test structure that produces Figure 13. The synthetic structure giving rise to Figure 16 has a crustal anomaly located $30 \mathrm{~km}$ (two blocks) south of the mantle anomaly. The ability of the inverse to reconstruct the offset in the structure argues that the 


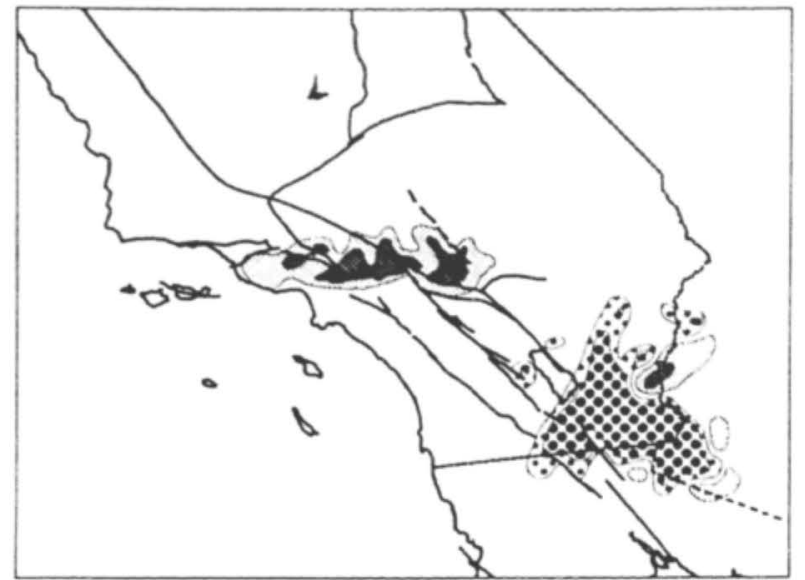

$0.30 \mathrm{~km}$

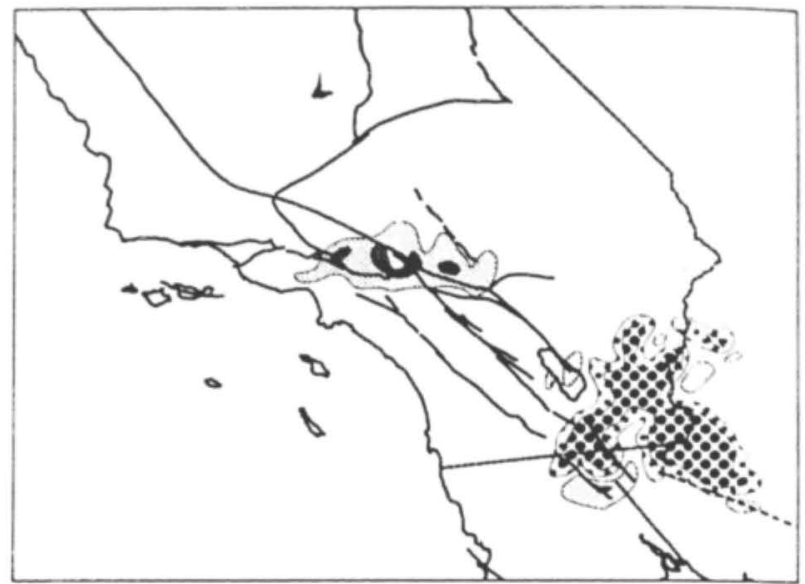

$30-60 \mathrm{~km}$

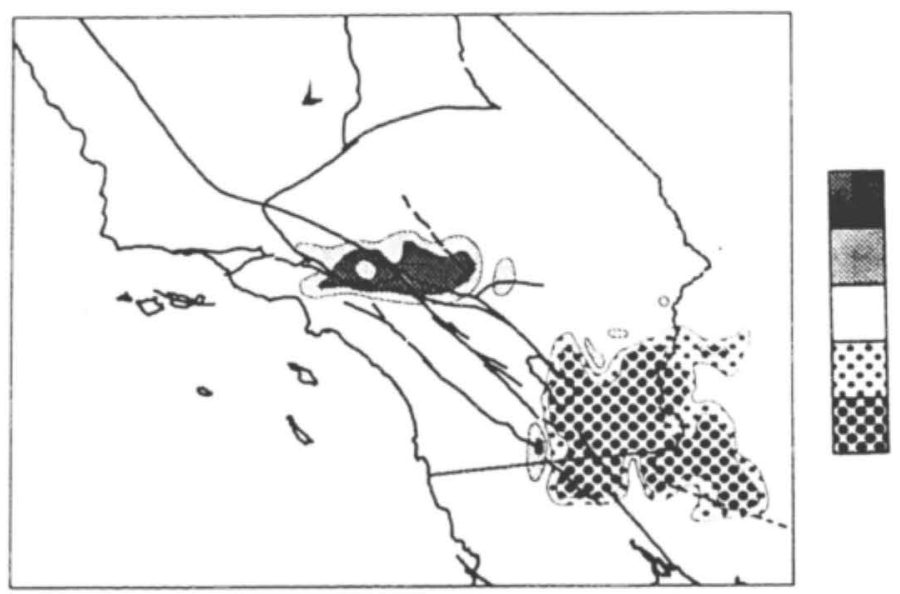

Fig. 14. The input structure is the same as Figure 13 except that the Transverse Ranges anomaly in the second layer of blocks has been made nonanomalous. In the inversion, some anomaly is artificially reconstructed in this layer, but it is markedly diminished in ampliude compared to Figure 13. Also the uppermost layer has been diminished in amplitude slightly compared to the inversion shown in Figure 13.

relatively southerly position of the eastem crustal Transverse Ranges anomaly in Figure 12 is not an artifact. Because the crustal anomaly does not correlate with topography or station correction terms for sediment or Moho position, we doubt these potential sources of error contribute to the observed feature.

Hearn and Clayton [1986a] have carefully investigated the seismic structure of the upper crust with the use of $P_{g}$ arrivals originating from local earthquakes. Their results show some similarity to those shown here, but the overall correlation is weak. $P_{\text {, }}$ rays sample only the upper $7-9 \mathrm{~km}$ of the crust while teleseismic rays uniformly sample the entire -30 -km-thick upper layer. This difference suggests that differences in the resulting crustal seismic velocity structure arise from lower crustal velocity variations.

Like the crustal Transverse Ranges anomaly, the crustal Salton Trough anomaly is not located directly above its deeper counterpart but is arially more extensive (see Figure 12). This relationship leads us to believe the crustal Salton Trough anomaly is also authentic and not simply a projection of deeper structure to the surface. When considered in conjunction with the lack of correlation between the crustal structure depicted in Figure 12 and the upper crustal obtained by Hearn and Clayton, this anomaly suggests that major differences exist between upper and lower crustal levels in the Salton Trough region.

To test whether the Transverse Ranges mantle anomaly results from anisotropic mantle oriented so as to allow vertically traveling teleseismic phases to arrive early, we examine two events of modest incidence angle ( $\Delta$ between $30^{\circ}$ and $35^{\circ}$, with angles less than $30^{\circ}$ from horizontal in the upper mantle). Figure 17 shows $P$ delay maps for these two events. In both cases, a zone of early arrivals corresponds to the high-velocity Transverse Ranges anomaly (though the delay patterns are complicated: for the event from the SE structure beneath Mexico apparently is being projected onto the surface of southernmost Califormis; for the event to the NW structure beneath the Great Valley is being projected beneath the western Mojave region). If the Transverse Ranges anomaly were due solely to anisotropy, shallow inclination rays passing through the anumaly would be delayed. In fact, the integrated advance of the arrivals passing through the Transverse Ranges anomaly is approxi- 

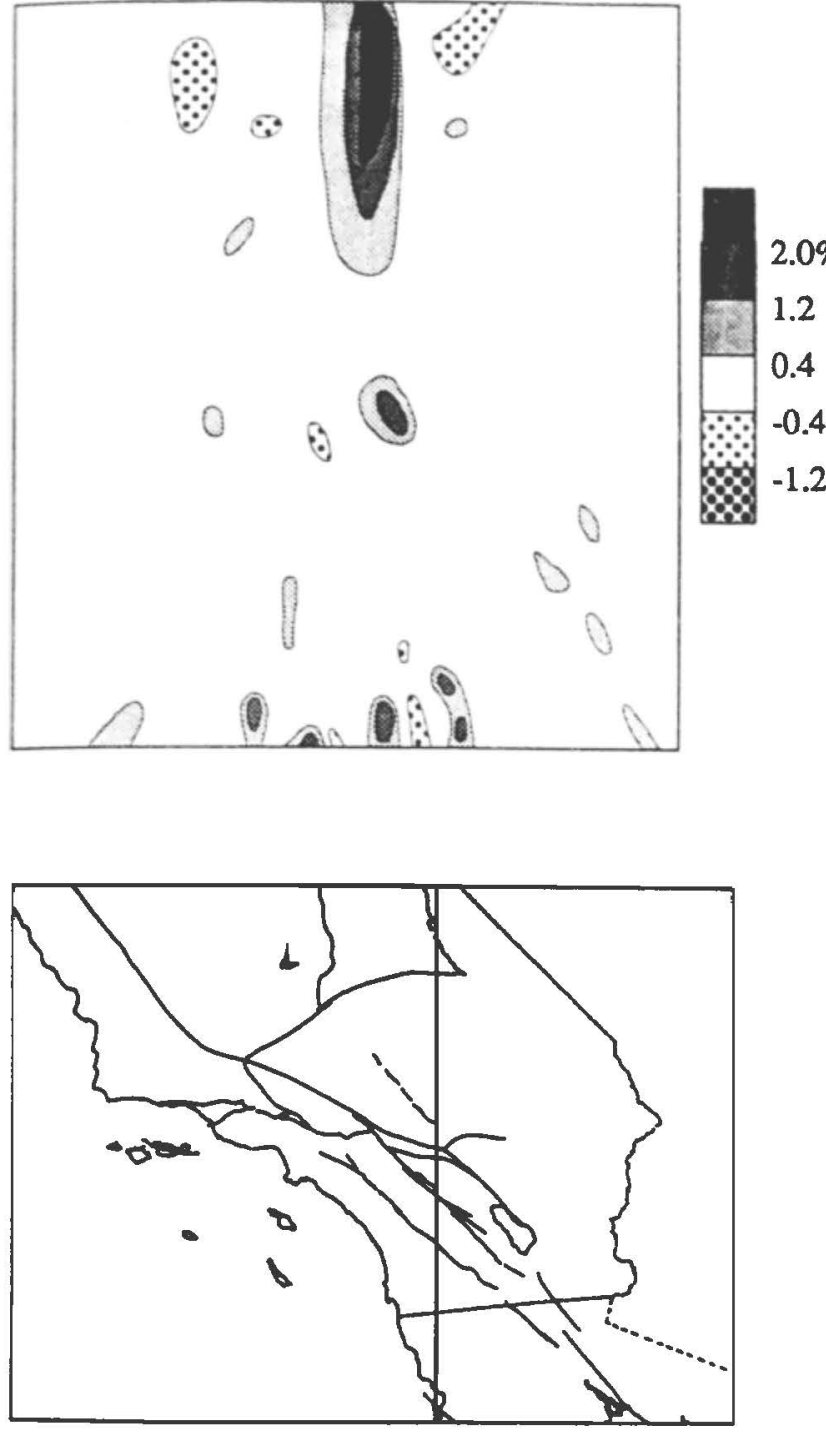

Fig. 15. Inversion of a test anomaly that is $3 \%$ fast on its right side and tupers linearly to zero anomaly on its left side. The inversion is disinetly symmetrical.

mately the same as that observed for arrivals of any incidence angle (compare to Figure 4), ruling out the possibility of a strong anisotropic contribution to the early $P$ arrivals.

Figure 12 indicates another large-amplitude, high-velocity anomaly beneath the southern Sierra Nevada. Ray coverage there is poor, especially in azimuthal completeness, and the inversion is poorly constrained. However, we can attain some control on the location of this anomaly through careful consideration of delays from stations in the area. The station located near Lake Isabella in the southern Sierra Nevada ("ISA" in Figure 3 ) displays greater variation in delay residual than any other station in the Southem California Seismic Array. The map of ISA's delay times as a function of ray parameter and back azimuth, shown in Figure 18, indicates that the anomalous region lies somewhere NNW of Lake Isabella, and extends south about as far as ISA, but not farther. This station delay map by itself gives no indication of the depth to the anomalous region, although the magnitude of the anomaly excludes the crust as a principal cause. Rather, the large magnitude of the feature suggests the presence of a large volume of anomalous mantle. This is supported by Figure $17 a$, where early arrivals are projocted into the southem Sierra Nevada and westem Mojave regions.

Figure 18 also displays delay maps from stations BMT and FRI. Station BMT (south of ISA) records strong regative delays for rays arriving shallowly from the NW (negative between ray parameter 7 and $10 \mathrm{deg} / \mathrm{s}$ ). Assuming that the same anomalous region produced the strong time advances at both ISA and BMT, the station separation of $-60 \mathrm{~km}$ requires the anomaly to lie beneath the Moho, though probably not deeper than $-300 \mathrm{~km}$. Located $190 \mathrm{~km} \mathrm{NW}$ of ISA, station FRI (not shown in Figure 3 and not used in the inversions shown above) records extremely early arrivals from the $\mathrm{SW}$, probably arising from the same anomaly. The late delays observed at
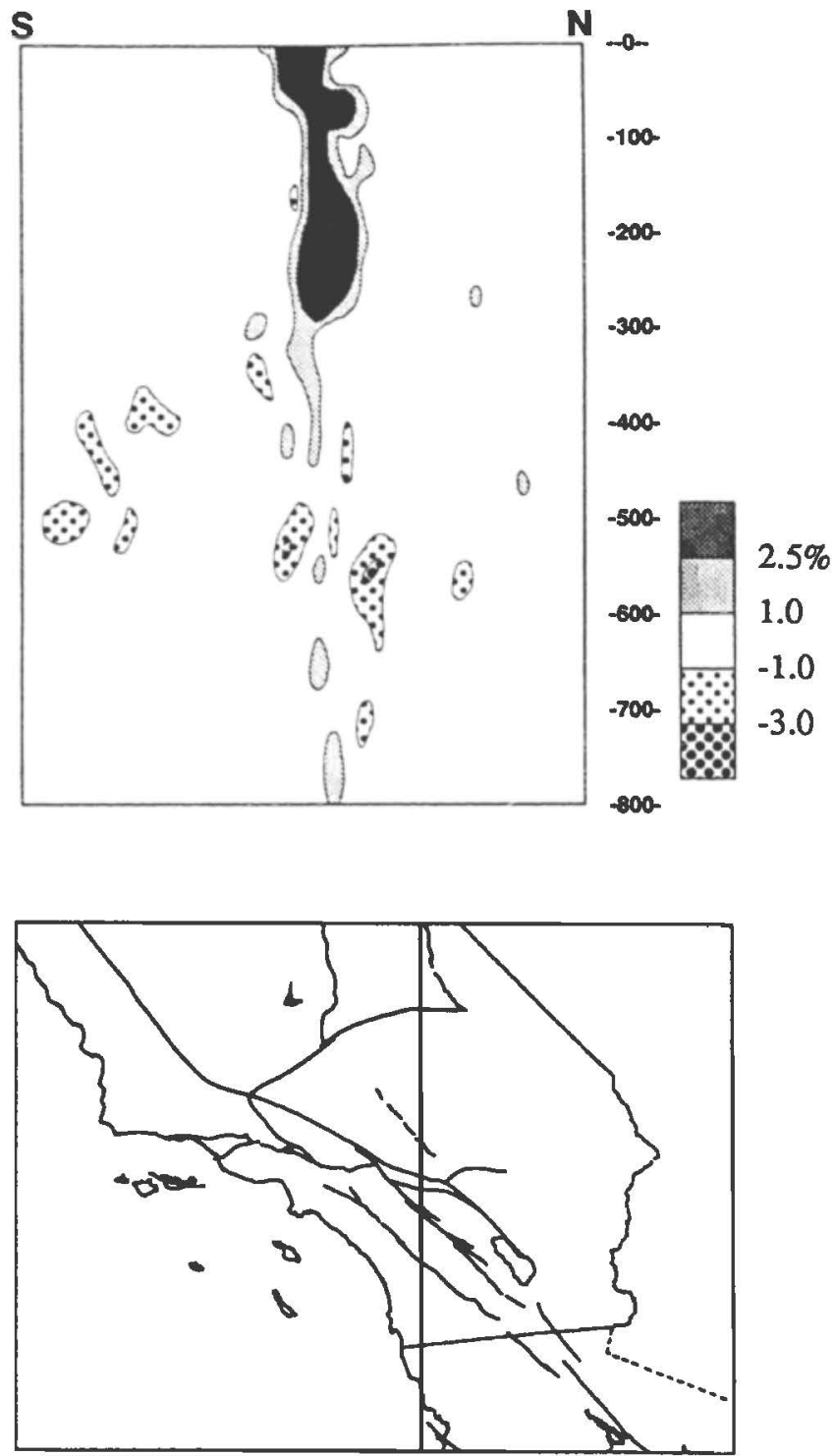

Fig. 16. The input structure is the same as Figure 13 except that the upper layer of the Transverse Ranges anomaly has been located two blocks farther to the south. It is seen in the inversion that the surface Transverse Ranges anomaly is well reconstructed in its offset position. 

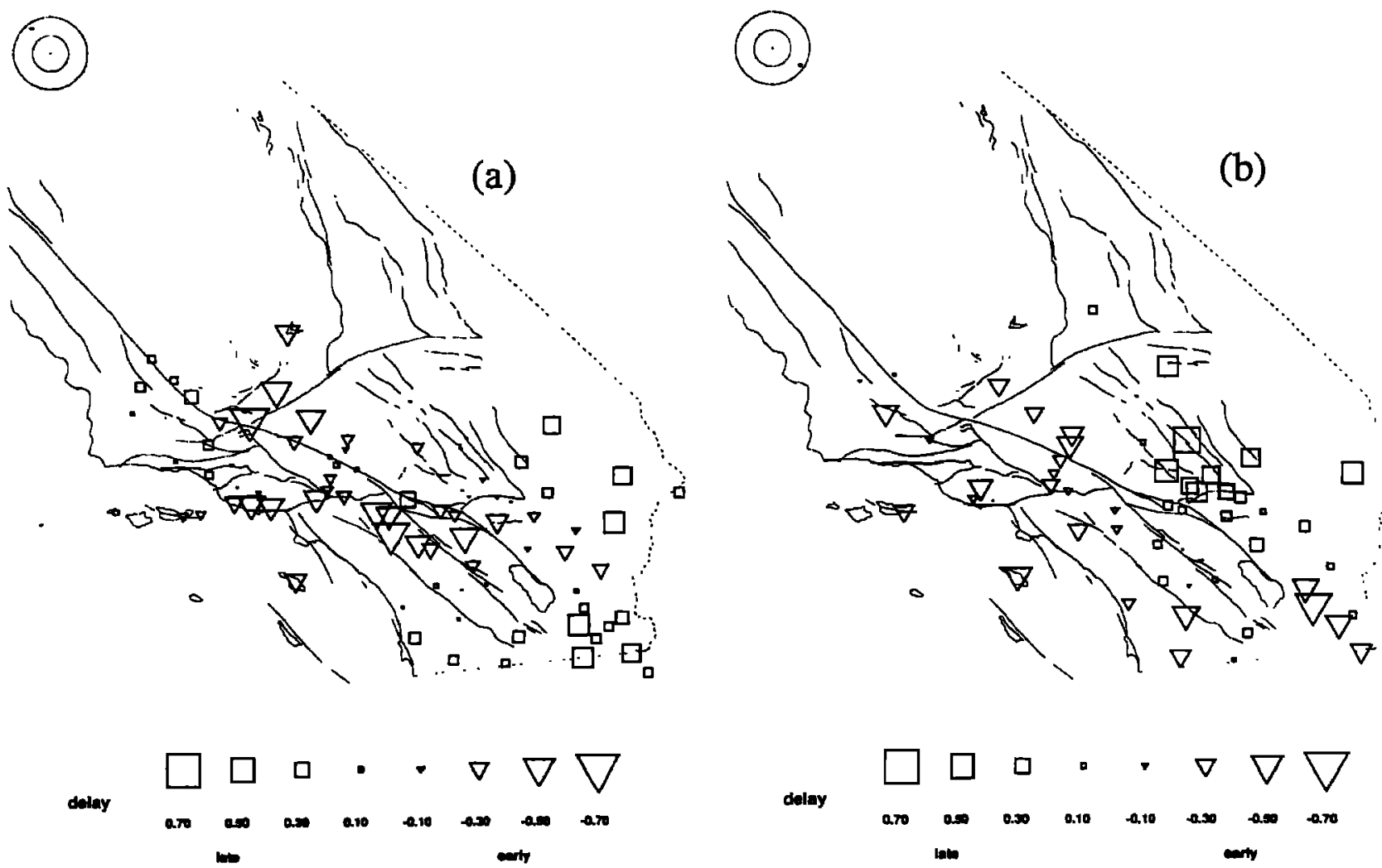

Fig. 17. Two $P$ delay maps resulting from two earthquakes occurring relatively close to southem Califomia $\left(\Delta=33^{\circ}\right)$. (a) The delay partem for an event in Alaska. (b) The delay pattern for an event in El Salvador. The polar plot indicates the ray parameter and back azimuth for each event, and the reference circles are at 5 and $10 \mathrm{~s} / \mathrm{deg}$. Note that the pattem of early arrivals associated with the Transverse Ranges anomaly shifts in location depending on the direction of the incoming rays, and the patiem of early arrivals caused by the Transverse Ranges anomaly is approximately the same as that observed for any other angle of incidence. This implies that the Transverse Ranges is not strongly anisocropic. Also note the extremely early arrivals to the southemmost stations for the El Salvador event. These times are not explained by the model, and they probably arise from strucuure beneath northemmost Mexico.

FRI also indicates that the mantle anomaly is confined to the region south of FRI.

\section{SUMMAARY AND DISCUSSION}

We have constructed a $P$ wave image of the upper $750 \mathrm{~km}$ beneath southern California. The imaged structure is associated with surface physiography and tectonics. In particular, a -60 $\mathrm{km}$ wide, $-3 \%$ high-velocity anomaly extends $\sim 120 \mathrm{~km}$ beneath the westem Transverse Ranges and $-250 \mathrm{~km}$ beneath the central Transverse Ranges. In addition, a 3-4\% low-velocity anomaly underlies the Salton Trough region to depths of $70-100 \mathrm{~km}$.

Figure 10 illustrates that our ability to resolve an anomalous feature depends critically upon the orientation of the feanure and that good ray coverage is necessary for full reconstruction of even advantageously oriented strucnure. We have shown that all the features described beneath southern Califomia, the Transverse Ranges and Salton Trough anomalies and the crustal features, are resolvable with the available ray set. Other feanures may exist that are imaged only weakly because information about them is contained only in the smaller eigenvalues of $\left(\mathbf{L}^{\mathrm{T}} \mathbf{L}\right)^{-1}$. However, the synthetic examples indicate that if a feature existed in a moderately well-interrogated region (hit quality greater than 0.18 ), it would be detectable in our inversion (even though its amplitude would not be reconstructed fully) unless it were a thin horizontal slab.
Figure 12 presents a structure for the region beneath southern Califomia that seems reasonable given the delay patterns observed (e.g., Figures 4 and 17) and the synthetic test inversions (Figures 13-16). However, suggestions exist in the data that, for one reason or another, some of the structure is not well imaged. In Figure 17b, for instance, the arrivals recorded in the SE comer of the array are very early, and because the event is from the $S E$, the earliness probably results from high-velocity and/or anisotropic mantle beneath NW Sonora. Also, while the variance reduction in the delays is very good $(85 \%)$, it is not as good as found with the synthetic data (typically 99\%). Structure of a smaller scale than the block size used in the inversion is probably a major contributor to this. We see, then, that "errors" in the inversion may arise not from what may have been inadvertently included in the imaged structure but rather from what may have been omitted.

Acknowledgments. We would like to thank Eric Ivans, Charlie Knox, Cliff Thurber, Ray Weldon, and anonymous reviewers for helpful comments on this paper. This research was supported by NSF grant EAR-8804953 and by NSF contract EAR83-51371 and USGS contract 14-08-0001-G1774. Contribution number 4932. Division of Geological and Planetary Sciences, Califomia Institute of Technology. 

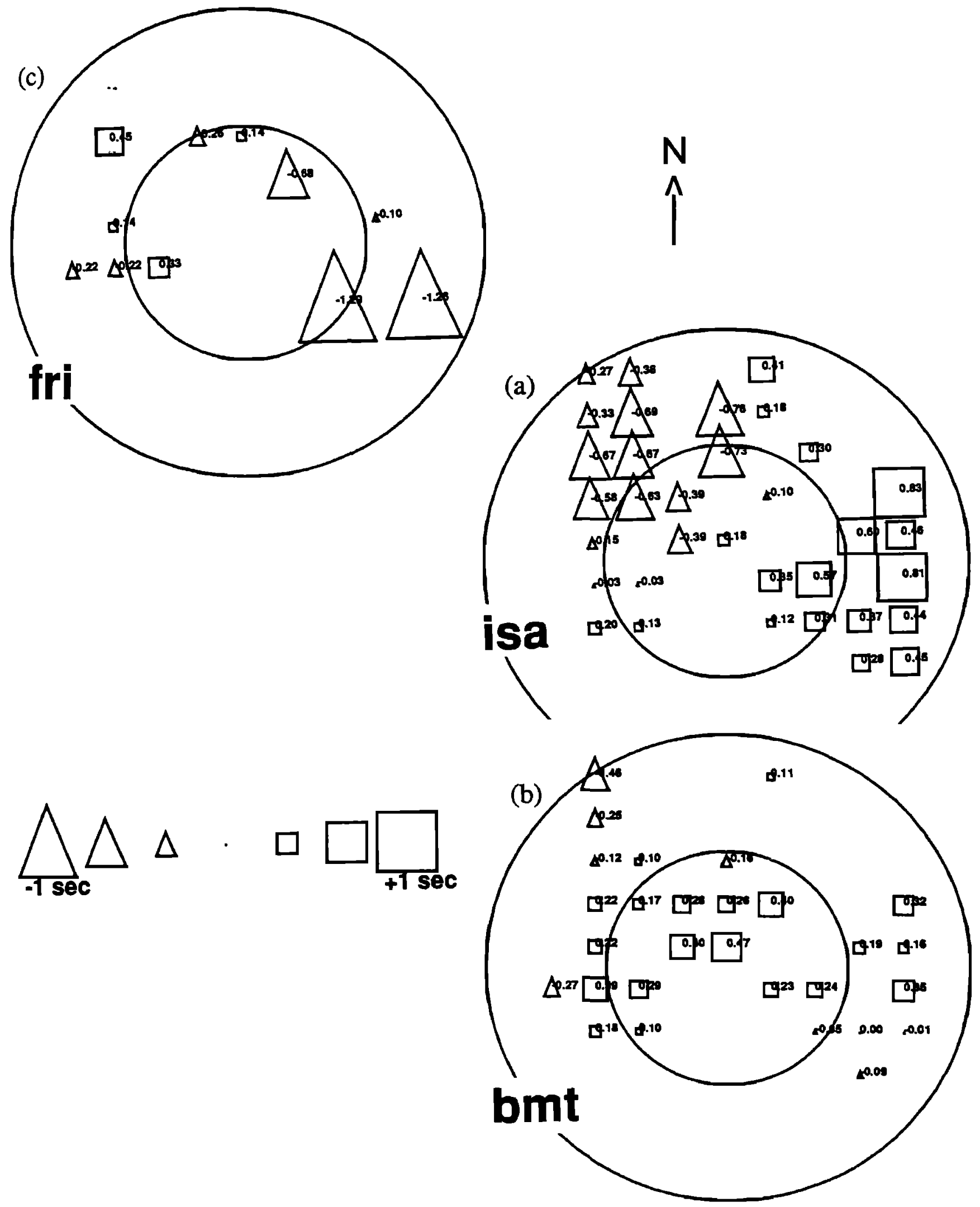

Fig. 18. Plots of delay time (in hundredths of a second) as a function of nay parameter and back azimuth for three stations near the southem Sierra Nevada. North is toward the top of the figure, and the circles represent 5 and $10 \mathrm{~s} / \mathrm{deg}$ for the inner and outer circles, respectively. Each number is the average of all measurements falling within the box centered on that number. (a) Delays wo station ISA, in the southem Sierra Nevada. (b) Delays to station BMT, which lies $-60 \mathrm{~km}$ south of ISA (see Figure 2). (c) Delays to station FRI, which lies $-190 \mathrm{~km}$ NW of ISA. Note thet the very early arivals observed in the NW part of the plot for ISA are apparently soen at BMT in the far NW part of that plot and are strongly represented in the SE part of the piot for FRI. 


\section{REFBRENCES}

Aki, K, A. Christoffersson, and E. S. Husebye, Determination of the three-dimensional seismic structure of the lithosphere, $J$. Geophys. Res., 82, 277-296, 1977.

Bird, P., and R. W. Rosenstock, Kinematics of present crust and mantle flow in southem Californin, Geol. Soc. Am. Bull., 95, 946-957, 1984.

DeMets, C., R.G. Gordon, S. Stein, and D.F. Argus, A revised estimate of Pacific-North Americe mocion and implications for westem North America plate boundary zone tectonics Geophys. Res. Lett., 14, 911 914, 1987.

Dueker, K G., and E. D. Humphreys, Upper-mantle velocity structure of the Great Basin, Geophys. Res. Lett., 17, 1327-1330, 1990.

Driewonski, A. M., and D. L Anderson, Travel times and station corrections for $P$ waves at teleseismic distances, J. Geophys. Res., 88 , 3295-3314, 1983.

Evans, J. R., Compressional wave velocity structure of the upper $350 \mathrm{~km}$ under the eastem Snake River plain near Rexburg, Idaho, J. Geophys. Res., 87, 2654-2670, 1982

Fuis, G. S., W. D. Mooney, J. H, Healy, G. A. McMechan, and W. J. Lutter, A seismic refraction study of the Imperial Valley region, Califormia, J. Geophys. Res., 89, 1165-1189, 1984.

Hadley, D. M, and H. Kanamori, Seismic strucrure of the Transverse Ranges, Califomia, Geol. Soc. Am. Bull., 88, 1461-1478, 1977.

Heam, T. M. $P_{n}$ travel times in southem Califomia, $J$. Geophys. Res., 89, 1843-1855, 1984

Heam, T. M., and R. W. Clayton, Lateral velocity variations in southem Califomia, I, Results for the upper crust from $P_{8}$ waves, Bull. Seismol. Soc. Am., 76, 495-509, 1986a.

Heam, T. M., and R W. Clayton, Lateral velocity variations in southem Califomia, II, Results for the lower crust from $P_{\text {a }}$ waves, Bull. Seismol. Soc. Am., 76, 511-520, 1986 b.

Herrin, E., Seismological tables for $P$ phases, Bull. Seismol. Soc. Am. 58, 1193-1241, 1968.

Humphreys, E D., and R. W. Clayton, Adaptation of tomographic reconstruction to seismic travel time problems, J. Geophys. Res., 93, 1073-1085, 1988.

Humphreys, E. D., R. W. Clayton, and B. H. Hager, A tomographic image of mantle structure beneath southem Califomia, Geophys. Res. Lett., 11, 625-627, 1984.
Iyer, H. M., A review of crust and upper mantle structure studies of the Snake River plain - Yellowstone volcanic system: A major lithospheric anomaly in the western U.S.A., Tectonophysics, 105, 291-308, 1984.

Namson, J., and T. L Davis, Structural transect of the westem Transverse Ranges, California: Implications for lithospheric kinematics and seismic risk evaluation, Geology, 16, 675-679, 1988.

Parker, E. C., P. M. Davis, J. R. Evans, H. M. Iyer, and K. H. Olsen, Upwarp of anomalous asthenosphere beneath the Rio Grande rifi Natwe, 312, 354-356, 1984

Raikes, S. A., Regional variations in upper manule structure beneath southem California, Geophys. J. R. Astron. Soc., 63, 187-216, 1980.

Rassmusen, J. R., and E. D. Humphreys, A tomographic image of the mantle beneath Washington, Geophys. Res. Lett., 15, 1417-1420, 1988.

Romanawicz, B. A., Seismic structure of the upper mantle beneath the United States by three-dimensional inversion of body wave amival times, J. Geophys., 57, 479-506, 1979.

Sheffels, B., and M. McNurt, Role of subsurface loads and regional compensation in the isostatic balance of the Transverse Ranges, Califormia: Evidence for intracontinental subduction. J. Geophys. Res., 91 6419-6431, 1986.

Walck, M. C., The P-wave upper mantle structure beneath an active spreading centre: the Gulf of Califomia, Geophys. J. R. astr. Soc., 76, 697-723, 1984.

Walck, M. C., and J. B. Minster, Relative array analysis of upper mantle lateral velocity variations in southem Califomia, J. Geophys, Res., 87, $1754-1772,1982$.

R. W. Clayton, Seismological Laboratory 252-21, California Institute of Technology, Pasadena. CA 91125.

E. D. Humphreys, Deparment of Geological Sciences, University of Oregon, Eugene, OR 97405.

(Received November 10, 1987;

revised June 6, 1990;

accepted June 13, 1990) 